\title{
Application of multifunctional targeting epirubicin liposomes in the treatment of non-small-cell lung cancer
}

This article was published in the following Dove Press journal:

International Journal of Nanomedicine

II October 2017

Number of times this article has been viewed

\author{
Xiao-li Song' \\ Rui-jun Ju² \\ Yao Xiao' \\ Xin Wang' \\ Shuang Liu' \\ Min Fu' \\ Jing-jing Liu' \\ Li-yan $\mathrm{Gu}^{\prime}$ \\ Xue-tao $\mathrm{Li}^{\prime}$ \\ Lan Cheng'
}

'School of Pharmacy, Liaoning University of Traditional Chinese Medicine, Dalian, ${ }^{2}$ Department of Pharmaceutical Engineering, Beijing Institute of Petrochemical Technology, Beijing, China
Correspondence: Xue-tao Li; Lan Cheng School of Pharmacy, Liaoning University of Traditional Chinese Medicine, ShengmingI Road 77, Double D Port, Dalian II6600, Liaoning, China

Tel +8641185890170

Fax $+864 I I 85890 I 28$

Email lixuetao1979@I63.com;

chenglan1966@163.com

\begin{abstract}
Chemotherapy for aggressive non-small-cell lung cancer (NSCLC) usually results in a poor prognosis due to tumor metastasis, vasculogenic mimicry (VM) channels, limited killing of tumor cells, and severe systemic toxicity. Herein, we developed a kind of multifunctional targeting epirubicin liposomes to enhance antitumor efficacy for NSCLC. In the liposomes, octreotide was modified on liposomal surface for obtaining a receptor-mediated targeting effect, and honokiol was incorporated into the lipid bilayer for inhibiting tumor metastasis and eliminating VM channels. In vitro cellular assays showed that multifunctional targeting epirubicin liposomes not only exhibited the strongest cytotoxic effect on Lewis lung tumor cells but also showed the most efficient inhibition on VM channels. Action mechanism studies showed that multifunctional targeting epirubicin liposomes could downregulate PI3K, MMP-2, MMP-9, VE-Cadherin, and FAK and activate apoptotic enzyme caspase 3. In vivo results exhibited that multifunctional targeting epirubicin liposomes could accumulate selectively in tumor site and display an obvious antitumor efficacy. In addition, no significant toxicity of blood system and major organs was observed at a test dose. Therefore, multifunctional targeting epirubicin liposomes may provide a safe and efficient therapy strategy for NSCLC.
\end{abstract}

Keywords: octreotide, honokiol, chemotherapy, vasculogenic mimicry, tumor metastasis, targeting drug delivery

\section{Introduction}

Lung cancer is the leading cause of cancer-related mortality with a high morbidity. ${ }^{1}$ Non-small-cell lung cancer (NSCLC) represents the predominant subgroup of lung cancer with a high recurrence and metastasis rate. ${ }^{2,3}$ Common therapy options for NSCLC include surgery, radiation therapy, chemotherapy, or comprehensive therapies. Surgery is the most successful therapy option for patients diagnosed with the early stage of NSCLC. ${ }^{4}$ Now, gene therapy and immunotherapy have the potential to improve the outcome of NSCLC. However, the gene therapy is restricted by a lack of clinically relevant techniques to assess gene expression in patients, and the cost of immunotherapy remains high as compared to regular cytotoxic therapy. ${ }^{5,6}$ Hence, chemotherapy is still an important antitumor strategy in the inoperable NSCLC. Unfortunately, the prognosis of regular chemotherapy is usually unsatisfactory due to a series of situations, including tumor metastasis, vasculogenic mimicry (VM) channels, limited killing of tumor cells, and severe systemic toxicity. ${ }^{7}$

VM channels were first found in highly aggressive and metastatic melanoma cells in $1999 .{ }^{8}$ Under the condition of hypoxia, tumor cells could directly form VM channels, thus facilitating tumor metastasis without the involvement of endothelial cells. ${ }^{9-11}$ 
VM channels have been observed in a variety of malignant tumors including NSCLC and may provide sufficient blood perfusion for the rapid tumor growth. Increasing studies indicated that a poor prognosis in lung cancer patients was associated with the emergence of the VM channels. ${ }^{12-14}$

Tumor metastasis is the main feature of malignant tumors and is often considered to be the most lethal property of tumors. ${ }^{12,15}$ Metastasis is a complicated cell biological procedure that involves decreased adhesion between tumor cells, damages in extracellular matrix structure, movement of tumor cells, and formations of new blood vessels. ${ }^{16,17}$ Meanwhile, tumor cells involve coordinated expression of various factors and then produce abundant hydrolytic enzymes that can degrade extracellular matrix and damage basement membrane, thus escaping from the basement membrane and migrating and colonizing in the distant organs. ${ }^{15,18}$ It was reported that the inhibition of tumor metastasis could remarkably enhance survival rates of tumor patients. ${ }^{19}$

Octreotide (OCT) is a synthetic 8-peptide analog of somatostatin and mainly binds to somatostatin receptors that are overexpressed in a variety of tumors. ${ }^{20,21}$ Somatostatin receptors have been recognized as tumor markers and are used for tumor diagnose and treatment. ${ }^{22}$ Compared with natural somatostatin, OCT shows more advantages, including longer half-life, more metabolic stability, and specificity. ${ }^{23,24}$ Honokiol is an active compound isolated from traditional Chinese herb Magnolia officinalis. ${ }^{25}$ It exhibits a variety of strong antitumor activities, including pro-apoptotic activity, anti-angiogenesis, anti-metastasis, and anti-proliferation in several types of tumors. ${ }^{26,27}$ Epirubicin is an anthracycline derivative of doxorubicin and has been clinically applied in treating many kinds of tumors via inhibiting synthesis of DNA and RNA. ${ }^{28,29}$ However, the use of free epirubicin is rather restricted due to the limited targeting effects and the severe side effects in chemotherapy.

In the present study, we synthesized polyethylene glycol-distearoyl phosphatidylethanolamine-octreotide (DSPE-PEG ${ }_{2000}-\mathrm{OCT}$ ) via an acylation reaction in which one of the amino groups on OCT was reacted with the N-hydroxysuccinimide (NHS) group of DSPE-PEG ${ }_{2000}-\mathrm{NHS}$. A kind of multifunctional targeting epirubicin liposomes was prepared to offer a comprehensive strategy for treating NSCLC. In the targeting liposomes, OCT was modified on the liposomal surface for achieving receptor-mediated targeting effects, honokiol was encapsulated into the lipid bilayer for inhibiting tumor metastasis and eliminating VM channel formations, and epirubicin was entrapped into the hydrophilic inner core as an antitumor drug. The codelivery of epirubicin and honokiol in one liposome could carry the antitumor agent and metastasis inhibitor into tumor tissues simultaneously. The objectives of the study were to construct the multifunctional targeting epirubicin liposomes and to evaluate destroying effects on VM channels, blocking effects on tumor metastasis, and the antitumor efficacy in vitro and in vivo.

\section{Materials and methods Reagents and cell lines}

Epirubicin hydrochloride and honokiol were obtained from Meilun Biotechnology Co., Ltd. (Dalian, China). OCT was synthesized by Shanghai Apeptide Co., Ltd. (Shanghai, China). Egg yolk phosphatidylcholine (EPC) and cholesterol were purchased from Avanti Polar Lipids, Inc. (Alabaster, AL, USA). DSPE-PEG ${ }_{2000}$ and DSPE-PEG ${ }_{2000}$-NHS were obtained from NOF Corporation (Tokyo, Japan). Hoechst 33258 and 1,1-dioctadecyl-3,3,3,3-tetramethylindotricarbocyanine iodide (DiR) were purchased from Nanjing Kaiji Biological Technology Development Co., Ltd. (Nanjing, China). Other chemicals were of analytical or chromatographic grade. Fetal bovine serum (FBS) and DMEM were ordered from GIBCO (Billings, MT, USA). Lewis lung tumor (LLT) cells were obtained from the Institute of Basic Medical Science, Chinese Academy of Medical Science (Beijing, China), and maintained in DMEM supplemented with $10 \% \mathrm{FBS}, 100 \mathrm{U} / \mathrm{mL}$ penicillin, and $100 \mu \mathrm{g} / \mathrm{mL}$ streptomycin under an atmosphere of $5 \% \mathrm{CO}_{2}$ at $37^{\circ} \mathrm{C}$. C57BL/6 mice $(18-20 \mathrm{~g})$ were obtained from Liaoning Changsheng Biotechnology Co., Ltd. (Benxi, China). Animal experimental procedures were performed according to the guidelines of Institutional Authority for Laboratory Animal Care of Liaoning University of Traditional Chinese Medicine, and this research was approved by the Institutional Authority for Laboratory Animal Care of Liaoning University of Traditional Chinese Medicine.

\section{Synthesis of targeting molecules}

DSPE-PEG $_{2000}$-OCT conjugate was synthesized and characterized according to our previous report. ${ }^{30}$ Briefly, DSPE-PEG ${ }_{2000}$-NHS was incubated in anhydrous dimethylformamide with OCT at 1:1 molar ratio; $\mathrm{pH}$ of the solution was adjusted to 9 with an appropriate amount of N-methylmorpholine, followed by continuous stirring for 24 hours at room temperature (Figure S1). Product was purified by dialysis (molecular weight $[\mathrm{MW}]$ cutoff $=3,500 \mathrm{Da}$ ) against distilled water for 4 times (12 hours each time) to remove unconjugated raw materials. The resultant was then lyophilized and stored at $-20^{\circ} \mathrm{C}$ until use. To confirm the 
conjugation of DSPE-PEG $2000-\mathrm{OCT}$, the final product was assayed by a matrix-assisted laser desorption/ionizationtime-of-flight mass spectrometry (MALDI-TOF-MS; Bruker Daltonics, Bremen, Germany).

\section{Preparation of liposomes}

Liposomes were prepared according to our previous report. ${ }^{31}$ Briefly, a mixture of EPC, cholesterol, DSPE-PEG ${ }_{2000}$, DSPE-PEG ${ }_{2000}$-OCT, and honokiol (molar ratio $=60: 40: 2: 3: 5$ ) was dissolved in chloroform, then the organic solvent was removed by a rotary evaporation under vacuum at $40^{\circ} \mathrm{C}$, and the lipid film was subsequently hydrated with ammonium sulfate $(250 \mathrm{mM})$ by sonication in a water bath for 5 minutes. Subsequently, the suspensions were treated with an ultrasonic cell disruptor for 10 minutes $(200 \mathrm{~W})$. The liposomes were successively extruded through polycarbonate membranes with pore size of $200 \mathrm{~nm}$ for 3 times, thus producing the blank multifunctional targeting liposomes. The resulting blank liposomes were sealed in a dialysis tubing (MW cutoff $=12,000-14,000 \mathrm{Da}$ ), and the external buffer was exchanged with PBS ( $\mathrm{pH}=7.4)$ for 3 times over 24 hours. Active loading procedure was performed by incubating in water bath at $40^{\circ} \mathrm{C}$ with intermittent shaking for 20 minutes after the addition of free epirubicin (lipids/drug $=20: 1, \mathrm{w} / \mathrm{w}$ ). The multifunctional targeting epirubicin liposomes were then obtained.

Table S1 lists the final compositions of epirubicin liposomes, epirubicin plus honokiol liposomes, and OCTmodified epirubicin liposomes, and the following procedures were the same as those of multifunctional targeting epirubicin liposomes. DiR liposomes and multifunctional targeting DiR liposomes (lipids/DiR =200:1, w/w) were similarly prepared as fluorescence probes for evaluating the distribution in vivo.

\section{Characterization of liposomes}

Particle size, polydispersity index, and zeta potential value were measured by using a Nano Series Zen 4003 Zetasizer (Malvern Instruments Ltd., Malvern, UK). The morphology of multifunctional targeting epirubicin liposomes was observed by a transmission electron microscope (TEM; Tecnai G2 20ST; FEI Co., Tokyo, Japan) and an atomic force microscope (AFM; SPI3800N series SPA-400; NSK Ltd., Tokyo, Japan). In order to determine the encapsulation efficiency (EE) of liposomal formulations, the liposomes were eluted through a sephadex G-50 column to remove unloaded drug. Both epirubicin and honokiol were measured by using a high-performance liquid chromatography (HPLC) system (Agilent Technologies Inc., Cotati, CA, USA) at ultraviolet wavelengths of $254 \mathrm{~nm}$ and $294 \mathrm{~nm}$, respectively. Mobile phase was acetonitrile $/ 0.02 \mathrm{~mol} / \mathrm{L}$ sodium dihydrogen phosphate (volume ratio $=32: 68$ ) for epirubicin and methanol $/$ water (volume ratio $=70: 30$ ) for honokiol, respectively. The EE of epirubicin or honokiol was estimated using the following formula: $\mathrm{EE} \%=\left(\mathrm{W}_{\text {encap }} / \mathrm{W}_{\text {total }}\right) \times 100 \%$, where $\mathrm{W}_{\text {encap }}$ is the drug concentration in filtrated liposomes, and $\mathrm{W}_{\text {total }}$ is the drug concentration in unfiltrated liposomes. Each assay was repeated in triplicate.

In vitro release rates (RRs) of epirubicin and honokiol from the varying liposomes were analyzed by dialysis against PBS containing $10 \%$ plasma or normal saline. Briefly, $1.0 \mathrm{~mL}$ liposomes and $1.0 \mathrm{~mL}$ release medium were added into the dialysis tubing ( $\mathrm{MW}$ cutoff $=12,000-14,000 \mathrm{Da}$ ). After being sealed and immersed in $40 \mathrm{~mL}$ release medium, dialysis tubing was oscillated at $37^{\circ} \mathrm{C}$ with gentle shaking $(100 \mathrm{rpm})$. A volume of $0.5 \mathrm{~mL}$ release medium was sampled at 6,12 , 24 , and 48 hours, respectively. Then, the same volume of fresh release medium was replaced immediately after each sampling. ${ }^{31}$ The content of epirubicin or honokiol in samples was measured by using the HPLC method as described above. RR was calculated using the following formula: RR\% = (drug concentration at the time point/drug concentration in an equal volume of liposomes) $\times 100 \%$. Each assay was repeated in triplicate.

\section{Cytotoxic effects}

Sulforhodamine B (SRB) staining method was used to test the cytotoxic effects on LLT cells according to our previous report. ${ }^{31}$ Briefly, LLT cells were seeded at a density of $3 \times 10^{4}$ cells/well in 96-well culture plates and cultured for 24 hours under $5 \% \mathrm{CO}_{2}$ at $37^{\circ} \mathrm{C}$. In free drug treatment groups, fresh medium containing serial concentrations of drugs was added into the plate well, including free epirubicin, free honokiol, and the mixture of free epirubicin plus free honokiol. The concentration of epirubicin was in the range of $0-1.0 \mu \mathrm{M}$, and the ratio of epirubicin to honokiol was $1: 1$, $1: 3$, and 1:5, respectively. In liposome treatment groups, LLT cells were treated with blank multifunctional targeting liposomes, epirubicin liposomes, epirubicin plus honokiol liposomes, OCT-modified epirubicin liposomes, and multifunctional targeting epirubicin liposomes, respectively. The concentrations of epirubicin were in the range of $0-10.0 \mu \mathrm{M}$ (epirubicin/honokiol $=1: 5$, mole ratio). Cells incubated in culture medium were used as control. After incubation for 48 hours, the medium was replaced with $200 \mu \mathrm{L}$ ice-cold $10 \%$ trichloroacetic acid for 1 hour at $4^{\circ} \mathrm{C}$ and stained with 
$0.4 \%$ SRB for 20 minutes. Then, the cells were washed with $1 \%$ acetic acid to remove unbound dye, and the protein-bound dye was extracted with Tris base solution. Optical densities were measured by using a microplate reader (HBS-1096A; DeTie Laboratory Equipment, Nanjing, China) at a wavelength of $540 \mathrm{~nm}$. The survival rates of LLT cells were calculated using the following formula: survival $\%=\left(\mathrm{Abs}_{540}\right.$ of treated cells $/ \mathrm{Abs}_{540}$ of control cells) $\times 100 \%$, where $\mathrm{Abs}_{540}$ is the absorbance measured at $540 \mathrm{~nm}$. All assays were performed in triplicate, and 6 determinations were set for each dose level. Finally, the dose-effect curves were created. $\mathrm{IC}_{50}$ values were calculated using GraphPad Prism software Version 6.0 (GraphPad Software Inc., La Jolla, CA, USA).

\section{Cellular uptake and targeting effects in LLT cells}

LLT cells were seeded in 6-well plates at a density of $2 \times 10^{5}$ cells per well and incubated at $37^{\circ} \mathrm{C}$ under $5 \% \mathrm{CO}_{2}$ for 24 hours. The confluent cells were incubated with varying liposomal formulations for 4 hours, including epirubicin liposomes, epirubicin plus honokiol liposomes, OCT-modified epirubicin liposomes, and multifunctional targeting epirubicin liposomes, respectively. The final concentration of epirubicin was $5 \mu \mathrm{M}$. Meanwhile, cells treated with culture medium were used as blank control. The cells were washed 3 times with cold PBS, trypsinized, and harvested in $300 \mu \mathrm{L}$ PBS. Mean intensity of red fluorescence was measured by using a FACScan flow cytometer (Becton Dickinson, San Jose, CA, USA) with the events collected with $1 \times 10^{4}$ cells. Each assay was repeated in triplicate.

For the receptor competitive inhibition experiment, free OCT was added into the medium at a concentration of $5 \mathrm{mM}$, and LLT cells were preincubated for 1 hour. Then, the cells were incubated with varying liposomal formulations at $37^{\circ} \mathrm{C}$. The cells were then rinsed, trypsinized, and collected in $300 \mu \mathrm{L}$ PBS. The intracellular epirubicin distribution was measured as described above.

To visualize the cellular uptake of multifunctional targeting epirubicin liposomes, LLT cells were seeded in chambered coverslips at a density of $8 \times 10^{5}$ cells per well. After incubation for 24 hours, the cells were exposed to varying liposomal formulations for 4 hours, including epirubicin liposomes, epirubicin plus honokiol liposomes, OCTmodified epirubicin liposomes, and multifunctional targeting epirubicin liposomes, respectively. The final concentration of epirubicin was $5 \mu \mathrm{M}$. Culture medium was used as blank control. The cells were washed 3 times with cold PBS and fixed with $4 \%$ paraformaldehyde at a room temperature for
10 minutes, and nuclei were stained with Hoechst 33258 ( $2 \mu \mathrm{g} / \mathrm{mL}$ ) for 10 minutes in the darkness. Then, the fluorescent signals were imaged with a fluorescence microscope (Leica, Heidelberg, Germany).

\section{Destroying effects on VM channels}

A Matrigel ${ }^{\circledR}$-based tube formation assay was carried out to evaluate the destroying effects on VM channels. Briefly, the Matrigel was thawed at $4^{\circ} \mathrm{C}$, and $50 \mu \mathrm{L}$ of Matrigel was plated onto 96-well plates and incubated for 30 minutes at $37^{\circ} \mathrm{C}$ until Matrigel solidification. LLT cells $\left(4 \times 10^{4}\right.$ cells/well) were resuspended with serum-free DMEM and then loaded on the top of the Matrigel in a final volume of $200 \mu \mathrm{L}$. Then, epirubicin liposomes, epirubicin plus honokiol liposomes, OCT-modified epirubicin liposomes, and multifunctional targeting epirubicin liposomes were separately added into the culture system. The final concentration of epirubicin was $10 \mu \mathrm{M}$ (epirubicin/honokiol =1:5, mole ratio). Culture medium was used as blank control. After incubation for 4 hours, the VM channels were detected and photographed using an inverted microscope (XDS-1B; Chongqing Photoelectric Co., Ltd., Chongqing, People's Republic of China).

\section{Blocking effects on tumor metastasis and wound healing in vitro}

The migration in vitro assays were performed in a 12-well Transwell $^{\circledR}$ (Corning, NY, USA). Briefly, $1 \times 10^{5}$ LLT cells were added into each upper chamber with $200 \mu \mathrm{L}$ serumfree DMEM, and then, $600 \mu \mathrm{L}$ DMEM containing 10\% FBS was added into each lower chamber as a chemoattractant. The varying liposomal formulations were added into the top chambers at a concentration of $10 \mu \mathrm{M}$ epirubicin (epirubicin/ honokiol =1:5, mole ratio), including epirubicin liposomes, epirubicin plus honokiol liposomes, OCT-modified epirubicin liposomes, and multifunctional targeting epirubicin liposomes, respectively. Transwell chambers were incubated for 24 hours at $37^{\circ} \mathrm{C}$ under $5 \% \mathrm{CO}_{2}$. The cells in the upper chamber were removed by wiping with a cotton swab, and the migrant cells were fixed with cold $4 \%$ paraformaldehyde for 20 minutes, stained with $0.1 \%$ crystal violet for 30 minutes, and washed 3 times with PBS. The quantity of the migrant cells on the lower surface was evaluated and photographed under light microscopy from 3 random fields.

An in vitro wound healing assay was also carried out to evaluate the cell motility and migration according to our previous report. ${ }^{30}$ Briefly, LLT cells were first planted into 6 -well plates $\left(1 \times 10^{6}\right.$ cells/well $)$. When the cells spread to $60 \%-70 \%$, confluent cells were scored by using a micropipette tip with the same diameter. The plates were washed 
3 times with PBS to remove cell debris. Then, fresh medium containing the varying liposomal formulations was added, and the cells were allowed to migrate toward scratched portion for 24 hours. Culture medium was used as blank control. The images of wound closure were captured at 0,12 , and 24 hours using the inverted microscope. Wound healing was measured as the distance migrated by the leading edge of the wound at each time point.

\section{Regulating effects on VM protein indicators and apoptotic enzyme}

To study the action mechanism, PI3K, MMP-2, MMP-9, VE-Cadherin, FAK, and apoptotic enzyme caspase 3 in LLT cells were determined by using enzyme-linked immunosorbent assay kit (Cusabio Biotech Co. Ltd., Beijing, China). Briefly, LLT cells were cultured to $80 \%$ confluence and then treated with epirubicin liposomes, epirubicin plus honokiol liposomes, OCT-modified epirubicin liposomes, and multifunctional targeting epirubicin liposomes at a concentration of $10 \mu \mathrm{M}$ epirubicin, respectively. Culture medium was used as blank control. After incubation for 12 hours, the cells were harvested and lysed. Cell lysates were centrifuged at $12,000 \mathrm{rpm}$ at $4^{\circ} \mathrm{C}$ for 10 minutes. The samples were operated according to the manufacturer's instructions of the kits and analyzed by using a microplate reader at $450 \mathrm{~nm}$. The total protein concentrations were measured at $540 \mathrm{~nm}$ by a bicinchoninic acid kit. The expression ratio was calculated by using the following formula: expression ratio $=\left(A_{450 \mathrm{~nm}}\right.$ for treated cells $/ \mathrm{A}_{540 \mathrm{~nm}}$ for treated cells $) /\left(\mathrm{A}_{450 \mathrm{~nm}}\right.$ for control cells $/ A_{540 \mathrm{~nm}}$ for control cells), where $\mathrm{A}_{450 \mathrm{~nm}}$ and $\mathrm{A}_{540 \mathrm{~nm}}$ are the absorbance values. Each assay was repeated in triplicate.

\section{In vivo imaging in tumor-bearing mice}

To observe real-time distribution of the multifunctional targeting liposomes in LLT cells of xenograft mice, noninvasive optical imaging systems were used. DiR was encapsulated into liposomes as a fluorescence probe. C57BL/6 mice (6-8 weeks old, 18-22 g weight) were housed under standard laboratory conditions. Tumor-bearing mouse models were built according to our previous report. ${ }^{32}$ Briefly, $1 \times 10^{7}$ LLT cells were suspended in $200 \mu \mathrm{L}$ DMEM and injected into right forelimb flank of mice. When tumor volume reached $\sim 400-500 \mathrm{~mm}^{3}$, mice were injected with normal saline, free DiR, DiR liposomes, and multifunctional targeting DiR liposomes $(0.2 \mathrm{mg} / \mathrm{kg}$ ) via tail vein (3 per group). Mice were anaesthetized and scanned at 1, 3, 6, 12, and 24 hours using an in vivo image system (Carestream FX PRO; Carestream Health Inc., Rochester, NY, USA) equipped with an excitation band-pass filter at $750 \mathrm{~nm}$ and an emission at
$780 \mathrm{~nm}$. Exposure times were 60 seconds for X-ray images and 30 seconds for fluorescent images, respectively.

\section{Antitumor efficacy in tumor-bearing mice}

C57BL/6 mice were inoculated with LLT cells as described above. Treatments were initiated when tumor volume reached $100 \mathrm{~mm}^{3}$ ( $\sim 7$ days postinoculation). Tumor-bearing mice were randomly assigned to 6 groups and were intravenously administrated with normal saline, free epirubicin, epirubicin liposomes, epirubicin plus honokiol liposomes, OCT-modified epirubicin liposomes, and multifunctional targeting epirubicin liposomes, respectively. Treatments were undergone at a dose of $5 \mathrm{mg} / \mathrm{kg}$ epirubicin every other day for 4 times consecutively. Tumor size was measured by using a Vernier caliper. Tumor volume and tumor volume ratio were calculated by using the following formula: tumor volume $=\left(\right.$ width $^{2} \times$ length $) / 2$; tumor volume ratio $=$ tumor volume measured at ith day/tumor volume of the corresponding group at day 0 . Body weights and survival rates of tumor-bearing mice were measured every other day after first administration. Survival time was calculated from day 10 since tumor inoculation to death. Then, body weight changes and Kaplan-Meier survival curves were made. At day 22 after inoculation, the mice were euthanized to collect the livers, hearts, spleens, lungs, and kidneys. After being rinsed with PBS, the samples were fixed in 10\% formalin and embedded in paraffin blocks for later slicing $(5 \mu \mathrm{m}$ in thickness). The obtained sections were stained with H\&E and observed under an optical microscope for histopathological observations. Hematology parameters in the blood samples were measured to evaluate the preliminary toxicity after treatments with the varying formulations. At day 22 after inoculation, $20 \mu \mathrm{L}$ blood samples were collected from the retro-orbital sinus and analyzed by using a Hematology Analyzer (MEK-6318K; Nihon, Kohden, Japan).

\section{Statistics}

In this study, analyses were carried out by using the SPSS 17.0 software. Analysis of variance was used to determine the significance among groups, and $p<0.05$ was considered to be significant.

\section{Results \\ Synthesis and characterization of DSPE-PEG ${ }_{2000}-$ OCT}

Figure 1 shows the MALDI-TOF-MS spectra of DSPE$\mathrm{PEG}_{2000}$-NHS (Figure 1A) and DSPE-PEG ${ }_{2000}-\mathrm{OCT}$ conjugate (Figure 1B). Results showed that the average mass values of DSPE-PEG 2000 -NHS and DSPE-PEG $2000-\mathrm{OCT}$ 

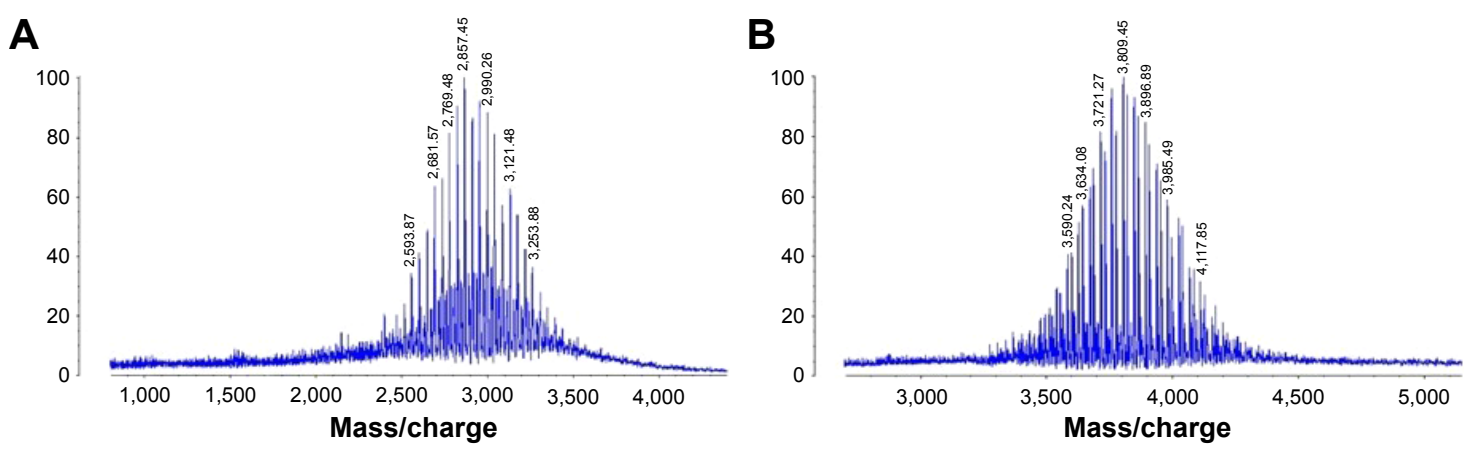

Figure I Characterization of targeting molecular.

Note: (A) MALDI-TOF-MS spectrum of DSPE-PEG 2000 -NHS, (B) MALDI-TOF-MS spectrum of DSPE-PEG $2000-\mathrm{OCT}$

Abbreviations: DSPE-PEG ${ }_{2000}$, polyethylene glycol-distearoyl phosphatidylethanolamine; MALDI-TOF-MS, matrix-assisted laser desorption/ionization-time-of-flight mass spectrometry; NHS, N-hydroxysuccinimide; OCT, octreotide.

were $\mathrm{m} / \mathrm{z} 2,857.45$ and $\mathrm{m} / \mathrm{z} 3,809.45$, respectively. The mass difference between the two molecules was corresponded to the mass of OCT, indicating a successful conjugation of DSPE-PEG $_{2000}-$ OCT.

\section{Characterization of liposomes}

Figure 2 shows the characterizations of multifunctional targeting epirubicin liposomes. Results from TEM and AFM confirmed that morphology of the targeting liposomes was almost spherical in nature (Figure $2 \mathrm{~A}$ and $\mathrm{B}$ ). The targeting liposomes were monodisperse with a diameter of $\sim 100 \mathrm{~nm}$ (Figure 2C). Table 1 lists particle sizes, polydispersity indexes, zeta potentials, and EEs of the varying liposomes. Results showed that the EEs of epirubicin and honokiol in all liposomal formulations were $>95.00 \%$. The average particle sizes were $\sim 100 \mathrm{~nm}$ with narrow polydispersity
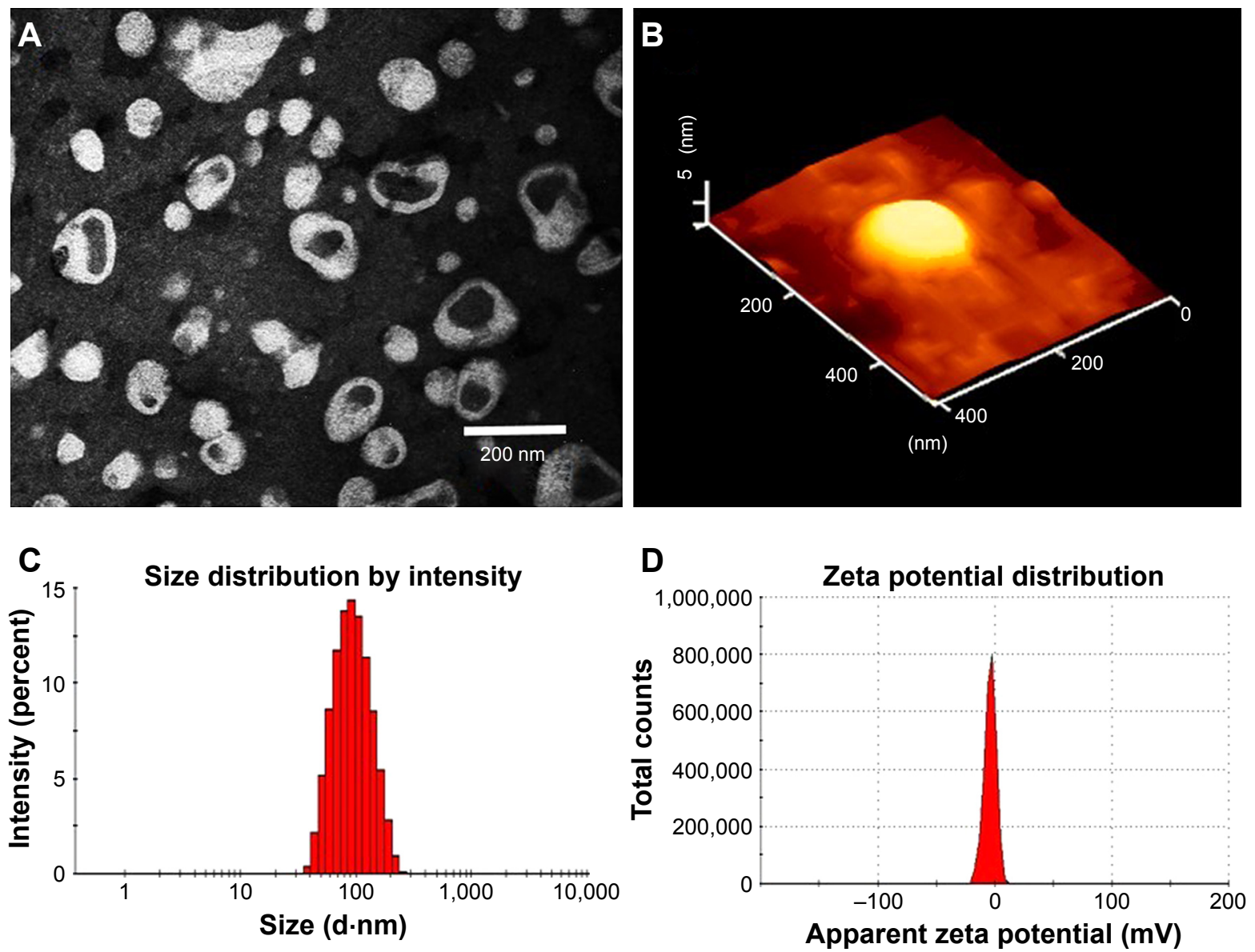

Figure 2 (Continued) 

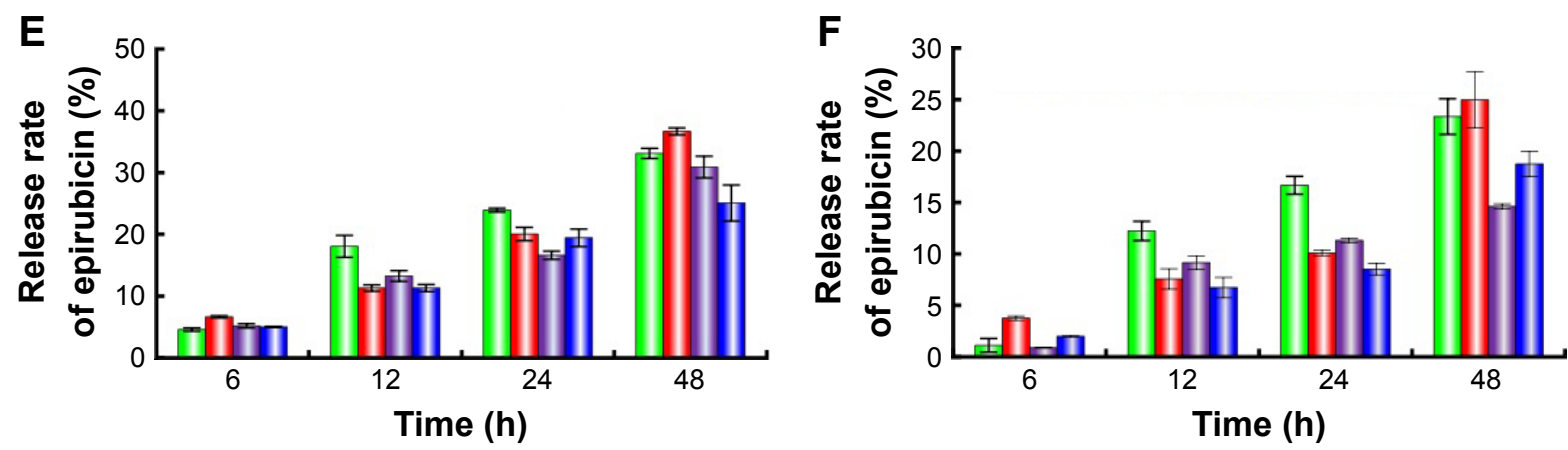

\begin{tabular}{ll}
\hline Epirubicin liposomes & D OCT-modified epirubicin liposomes \\
$\mathbf{0}$ Epirubicin plus honokiol liposomes & $\mathbf{0}$ Multifunctional targeting epirubicin liposomes
\end{tabular}
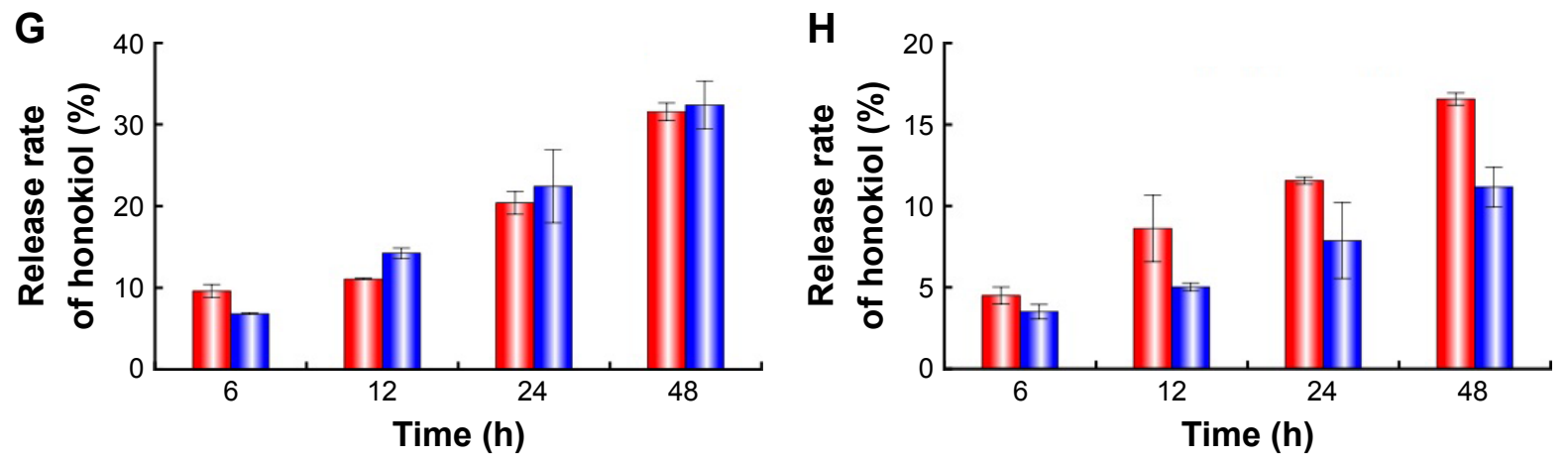

口 Epirubicin plus honokiol liposomes a Multifunctional targeting epirubicin liposomes

Figure 2 Characterizations of multifunctional targeting epirubicin liposomes.

Notes: (A) TEM image of multifunctional targeting epirubicin liposomes, Magnification $\times 50,000$. (B) AFM image of multifunctional targeting epirubicin liposomes, Magnification $\times 50,000$. (C) Particle size of multifunctional targeting epirubicin liposomes, (D) zeta potential of multifunctional targeting epirubicin liposomes, (E) release rate of epirubicin from varying formulations in PBS solution containing 10\% mouse plasma, (F) release rate of epirubicin from varying formulations in normal saline, (G) release rate of honokiol from varying formulations in PBS solution containing 10\% mouse plasma, $(\mathbf{H})$ release rate of honokiol from varying formulations in normal saline. Data are presented as mean \pm SD $(n=3)$. Abbreviations: AFM, atomic force microscope; OCT, octreotide; TEM, transmission electron microscope.

indexes $(\leq 0.20)$. The zeta potentials of all liposomal formulations were close to a neutral state with slightly negative charges. Figure 2E-H presents in vitro release results of the varying formulations in $10 \%$ plasma-containing PBS solution and in normal saline. Results showed that the RRs of epirubicin and honokiol increased obviously after the addition of plasma in release medium. For multifunctional targeting epirubicin liposomes, the RRs were $25.07 \% \pm 2.91 \%$ for epirubicin and $31.41 \% \pm 2.93 \%$ for honokiol at 48 hours in plasma-containing PBS solution, respectively.

\section{Cytotoxic effects}

Figure 3 illustrates the cytotoxic effects on LLT cells after treatments with varying formulations. Figure $3 \mathrm{~A}$ shows the cytotoxic effects of free drug on LLT cells. Results showed that epirubicin alone was effective in inhibiting the proliferation of LLT cells with a dose-dependent manner. After cotreated with epirubicin and honokiol (molar ratio $=1: 1,1: 3$, and 1:5), the survival rates of LLT cells were significantly decreased as compared with those treated with epirubicin alone at the same concentration. However, honokiol alone

Table I Characterization of liposomes

\begin{tabular}{|c|c|c|c|c|c|}
\hline & \multicolumn{2}{|c|}{ Encapsulation efficiency (\%) } & \multirow{2}{*}{$\begin{array}{l}\text { Particle } \\
\text { size }(\mathrm{nm})\end{array}$} & \multirow[t]{2}{*}{ PDI } & \multirow{2}{*}{$\begin{array}{l}\text { Zeta potential } \\
(\mathrm{mV})\end{array}$} \\
\hline & Epirubicin & Honokiol & & & \\
\hline Epirubicin liposomes & $97.89 \pm 0.08$ & & $106.23 \pm 0.47$ & $0.16 \pm 0.02$ & $-1.32 \pm 0.05$ \\
\hline Epirubicin plus honokiol liposomes & $98.89 \pm 0.12$ & $95.74 \pm 0.07$ & $107.16 \pm 3.11$ & $0.17 \pm 0.01$ & $-1.63 \pm 0.04$ \\
\hline OCT-modified epirubicin liposomes & $97.53 \pm 0.06$ & & $108.56 \pm 1.62$ & $0.18 \pm 0.04$ & $-2.36 \pm 0.04$ \\
\hline $\begin{array}{l}\text { Multifunctional targeting epirubicin } \\
\text { liposomes }\end{array}$ & $99.055 \pm 0.13$ & $96.41 \pm 0.04$ & $108.22 \pm 1.19$ & $0.18 \pm 0.02$ & $-3.23 \pm 0.04$ \\
\hline
\end{tabular}

Abbreviations: OCT, octreotide; PDI, polydispersity index 

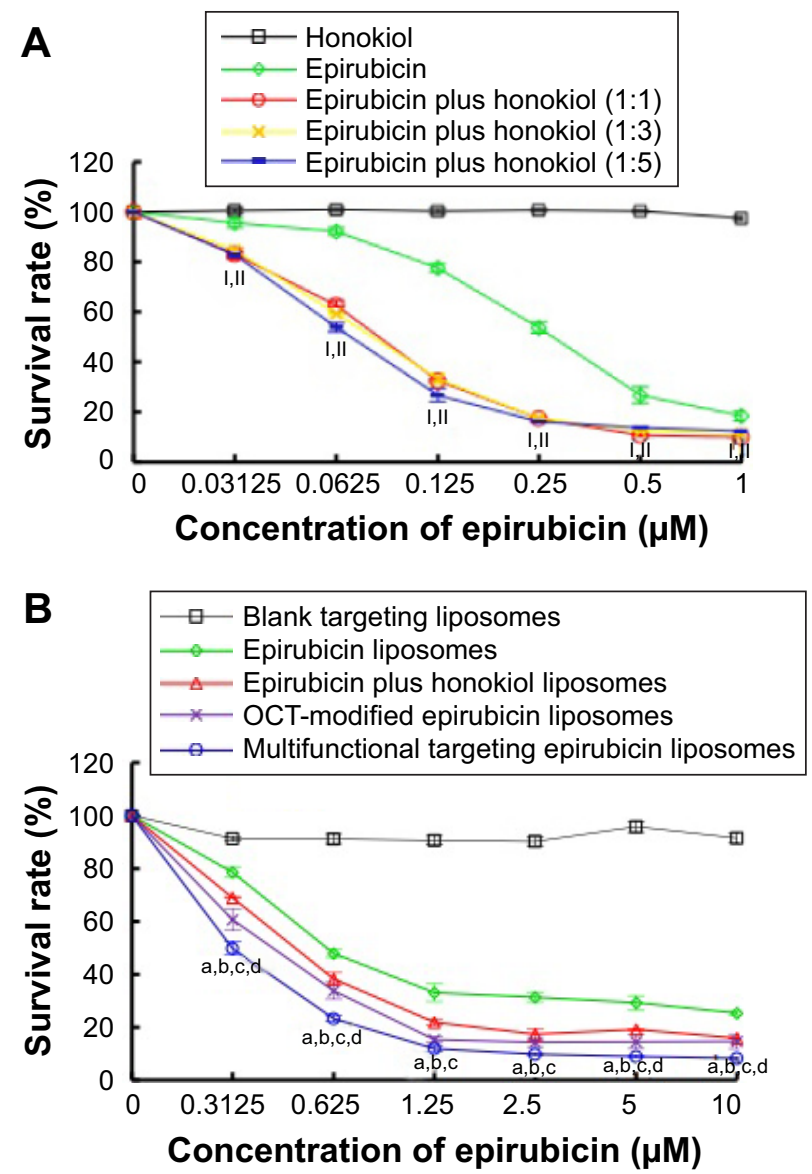
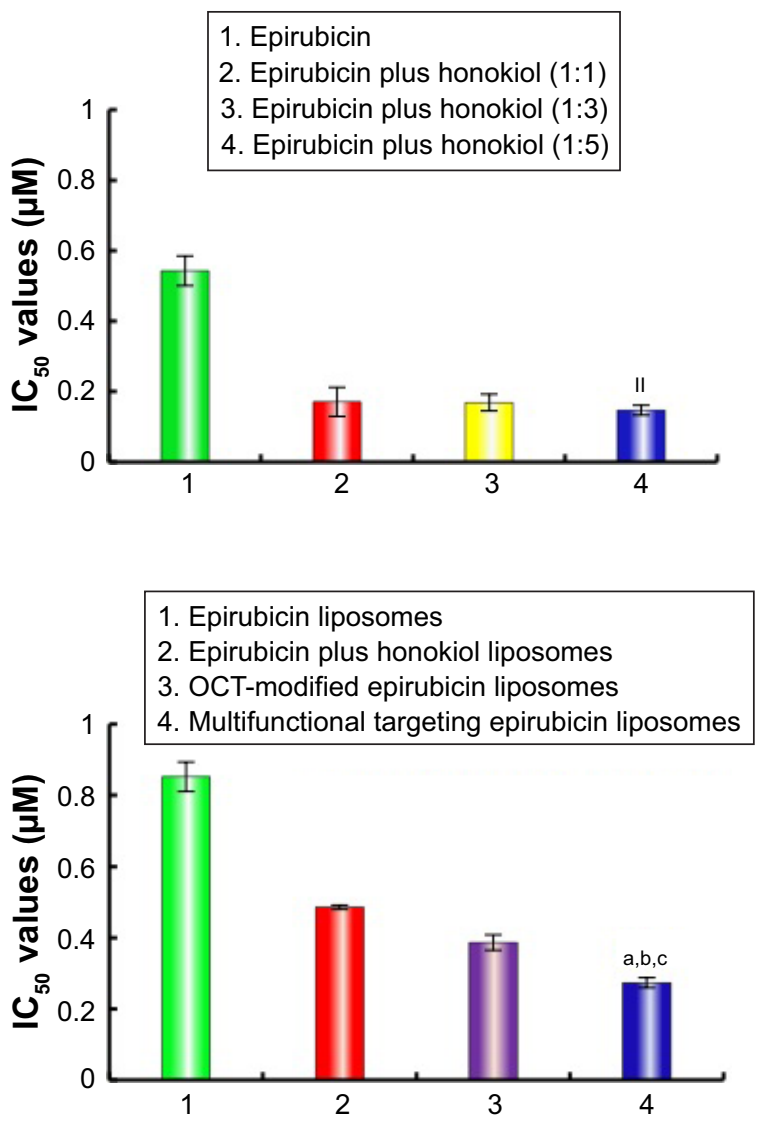

Figure 3 Inhibitory effects on LLT cells after treatments with the varying formulations.

Notes: (A) Inhibitory effects of free drugs, (B) inhibitory effects of liposomal formulations. $p<0.05$; I, vs free honokiol; II, vs free epirubicin; a, vs blank targeting liposomes; b, vs epirubicin liposomes; c, vs epirubicin plus honokiol liposomes; $d$, vs OCT-modified epirubicin liposomes. Data are presented as mean \pm SD ( $n=6$ ).

Abbreviations: LLT, Lewis lung tumor; OCT, octreotide.

showed negligible cytotoxicity to LLT cells. Figure 3B depicts the cytotoxic effects on LLT cells after treatments with liposomal formulations. Results showed that multifunctional targeting epirubicin liposomes exhibited the strongest cytotoxic effect on the proliferation among all the groups. Blank targeting liposomes exhibited minimal cytotoxic effect on LLT cells. Cytotoxic effect on LLT cells was increased with the increasing concentration of epirubicin displaying a dose-dependent manner. The rank of $\mathrm{IC}_{50}$ was multifunctional targeting epirubicin liposomes $<$ OCT-modified epirubicin liposomes $<$ epirubicin plus honokiol liposomes $<$ epirubicin liposomes.

\section{Cellular uptake and targeting effects in LLT cells}

Cellular uptake of the liposomes was measured by using flow cytometry (Figure 4A and B). Results showed that the geometric mean intensity values of LLT cells were $3.31 \pm 0.92$ for blank medium, $103.72 \pm 9.51$ for epirubicin liposomes, 200.86 \pm 7.13 for epirubicin plus honokiol liposomes, $222.81 \pm 6.14$ for OCT-modified epirubicin liposomes, and 261.5 \pm 4.01 for multifunctional targeting epirubicin liposomes. Multifunctional targeting epirubicin liposomes exhibited remarkably higher intracellular uptake compared with all other liposomes. Figure 4C and D shows the cellular uptake of the liposomes in the presence of free OCT. Results showed that little difference between with and without pretreating of free OCT for epirubicin liposomes and epirubicin plus honokiol liposomes and a significant shift of the fluorescence signal to the left were distinctly observed for OCT-modified epirubicin liposomes and multifunctional targeting epirubicin liposomes in the competitive inhibition study. Figure 4E illustrates the fluorescence images of epirubicin in LLT cells after treatments with the varying formulations for 4 hours. Results showed that the fluorescence intensity rank in LLT cells was multifunctional targeting epirubicin liposomes $>$ OCT-modified epirubicin liposomes $>$ epirubicin plus honokiol liposomes $>$ epirubicin liposomes. 


\section{Destroying effects on VM channels}

Figure 5A shows destroying effects on VM channels after treatments with the varying liposomal formulations. Results showed that LLT cells without any treatment formed the obvious vessel-like loops, channels, and networks after being seeded onto the Matrigel. Both multifunctional targeting epirubicin liposomes and epirubicin plus honokiol liposomes exhibited strong destroying effects on VM channels, and negligible destructions were observed after treatments with epirubicin liposomes and OCT-modified epirubicin liposomes.

\section{Blocking effects on tumor metastasis and wound healing in vitro}

Figure 5B exhibits the blocking effects on tumor metastasis after treatments with the varying liposomal formulations. After treatment with culture medium, LLT cells exhibited strong capability to cross membrane of Transwell. Compared with control group, multifunctional targeting epirubicin liposomes and epirubicin plus honokiol liposomes showed significant blocking effects on the migration of LLT cells.
Figure 6 displays the blocking effects on wound healing after treatments with the varying liposomal formulations. Compared with the initial wound scratch at 0 hour, LLT cells migrated into the denuded area at 24 hours in the culture medium. In contrast, multifunctional targeting epirubicin liposomes significantly inhibited the migration of LLT cells at 12 and 24 hours.

\section{Regulating effects of $\mathrm{VM}$ protein indicators and apoptotic enzyme}

Five VM protein indicators, including PI3K, MMP-2, MMP-9, VE-Cadherin, and FAK, were selected to investigate the action mechanism of multifunctional targeting epirubicin liposomes on VM channels. Figure 7 shows the regulatory effects on VM protein indicators and apoptotic enzyme in LLT cells after treatments with varying formulations. Results showed that the expression ratios of caspase 3 were enhanced to $1.51 \pm 0.12$ folds for epirubicin liposomes, $2.56 \pm 0.19$ folds for epirubicin plus honokiol liposomes, $1.81 \pm 0.22$ folds for OCT-modified epirubicin liposomes, and
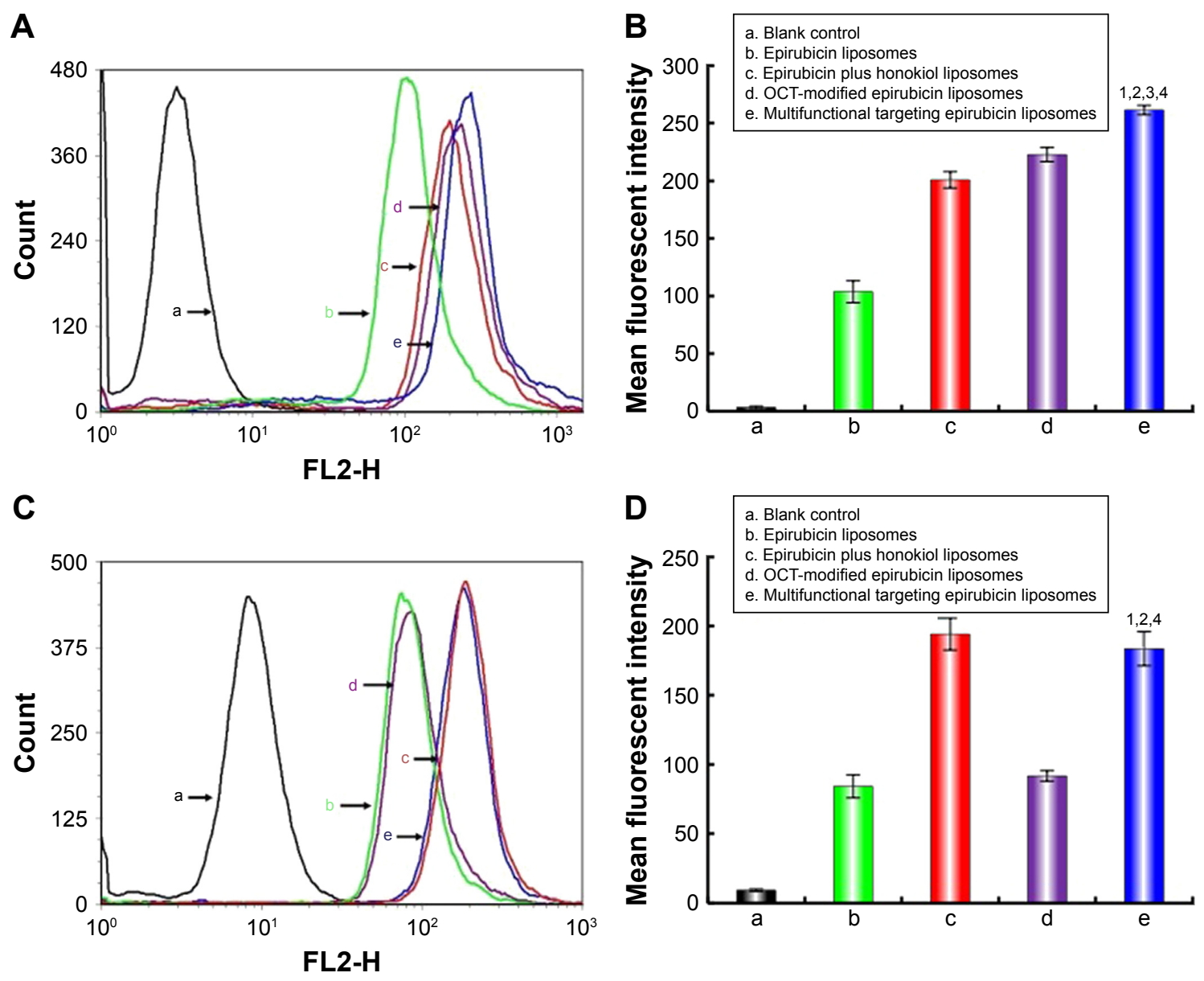

Figure 4 (Continued) 


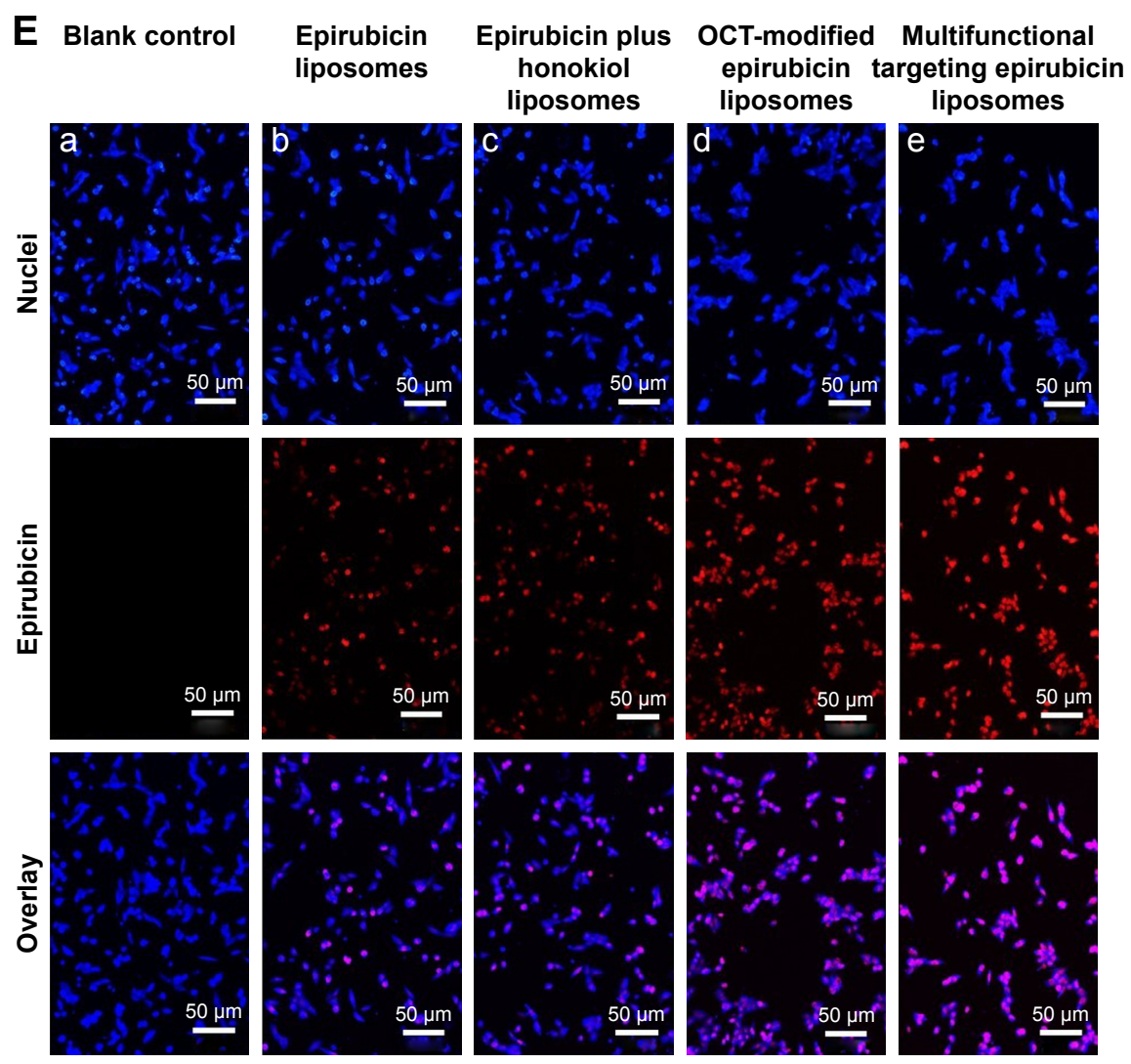

Figure 4 Intracellular uptake and targeting effects after incubation with varying formulations.

Notes: (A) Cellular uptake of LLT cells, (B) fluorescence intensity of epirubicin in LLT cells, (C) cellular uptake of LLT cells after incubation with excess OCT, (D) fluorescence intensity of epirubicin in LLT cells after incubation with excess OCT, (E) fluorescence microscopy images of LLT cells incubated with varying formulations. Magnification $\times 250$. a. Blank control; b. epirubicin liposomes; c. epirubicin plus honokiol liposomes; d. OCT-modified epirubicin liposomes; e. multifunctional targeting epirubicin liposomes. $p<0.05$; I, vs a; 2 , vs b; 3 , vs c; 4 , vs $d$.

Abbreviations: LLT, Lewis lung tumor; OCT, octreotide.
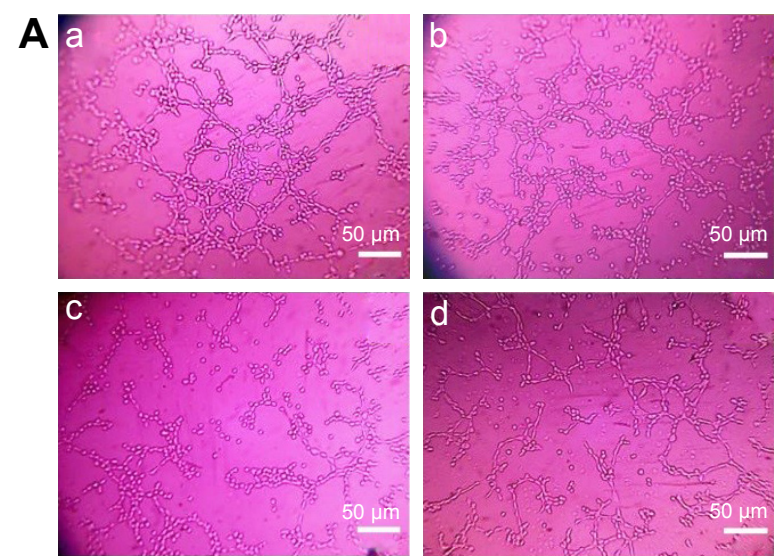

d
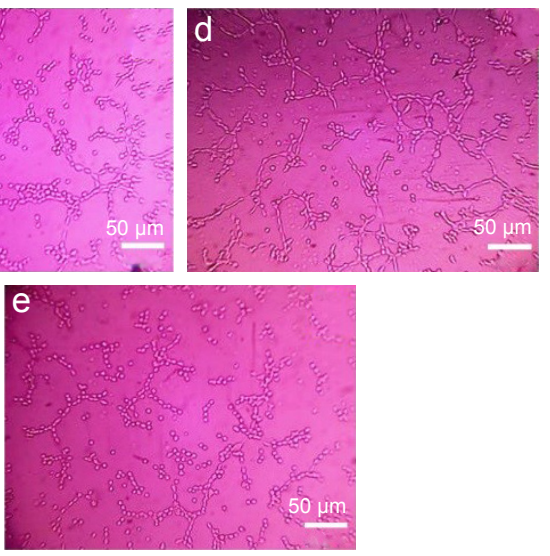
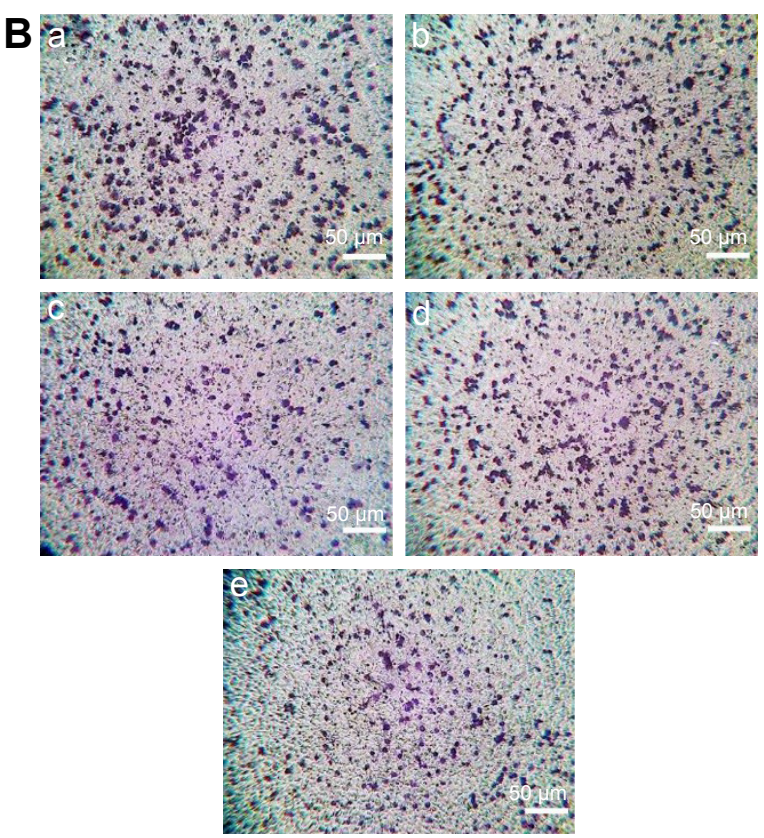

Figure 5 Destructive effects on VM channels and blocking effects on LLT cells migration in vitro after treatment with varying formulations.

Notes: (A) Destructive effects on VM channels, Magnification $\times 100$. (B) blocking effects on LLT cells migration. Magnification $\times 100$. a. Blank control; b. epirubicin liposomes; c. epirubicin plus honokiol liposomes; d. OCT-modified epirubicin liposomes; e. multifunctional targeting epirubicin liposomes.

Abbreviations: LLT, Lewis lung tumor; OCT, octreotide; VM, vasculogenic mimicry. 


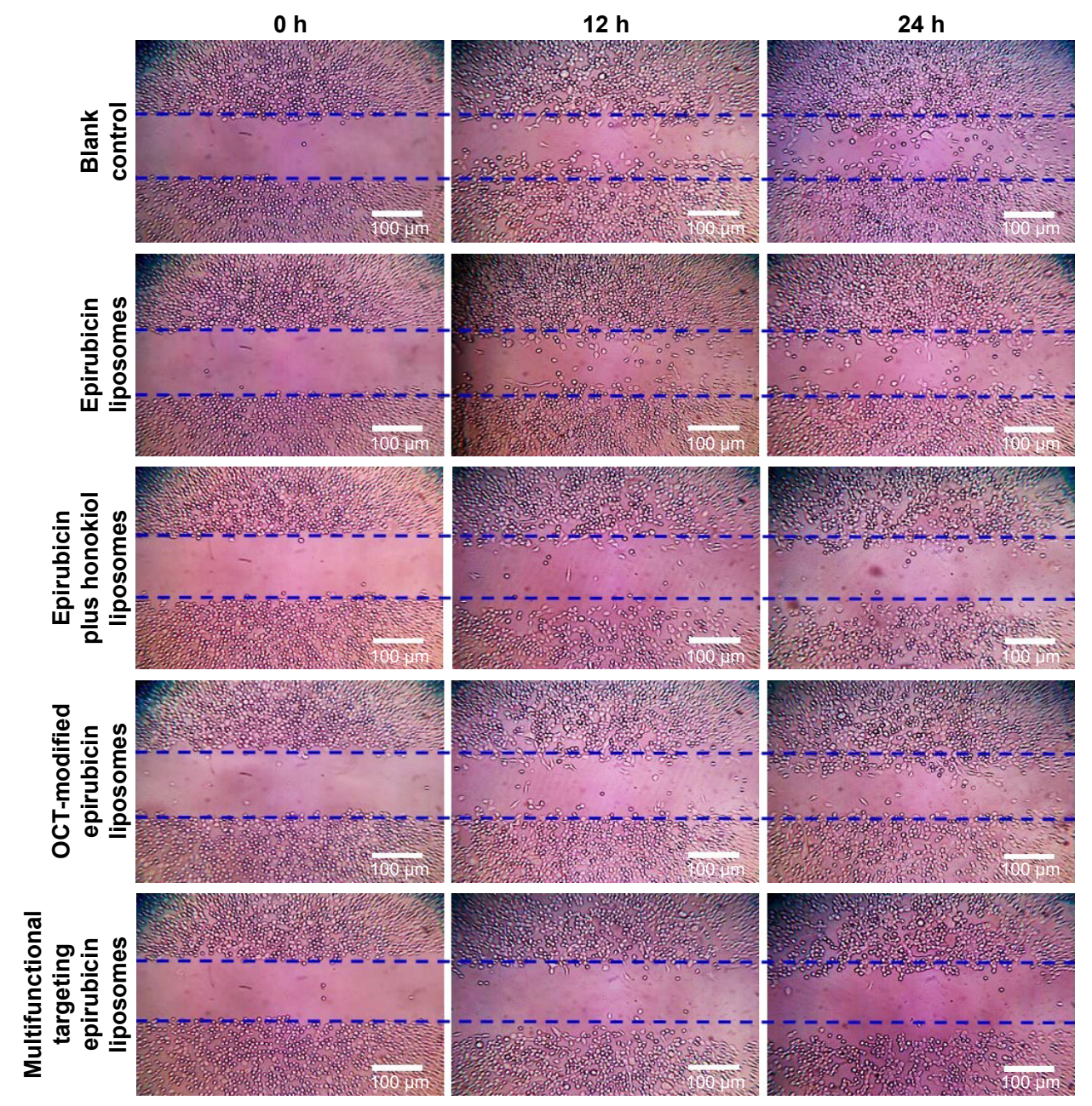

Figure 6 Blocking wound healing effects in LLT cells after treatments with the varying liposomal formulations. Magnification $\times 100$. Abbreviations: LLT, Lewis lung tumor; OCT, octreotide.

$2.97 \pm 0.10$ folds for multifunctional targeting epirubicin liposomes. Compared with epirubicin liposomes, multifunctional targeting epirubicin liposomes significantly downregulated the expressions of PI3K (Figure 7B), MMP-2 (Figure 7C), MMP-9 (Figure 7D), VE-Cadherin (Figure 7E), and FAK (Figure 7F).

\section{In vivo imaging in tumor-bearing mice}

Biodistribution of multifunctional targeting liposomes was evaluated by in vivo fluorescence imaging, and Figure 8 shows the real-time imaging observation after intravenous administration of varying DiR formulations. Results showed that strong fluorescent signals were observed in blood circulation and in tumor location after the administration of multifunctional targeting DiR liposomes, and fluorescent signals were maintained up to 24 hours in tumor location. By contrast, the fluorescent signal in tumor location cannot be detected at 24 hours in group of DiR liposomes. Free DiR was mainly distributed in liver, and no signal was detected in tumor location, indicating that free DiR had no specificity to tumor tissues.

\section{Antitumor efficacy in tumor-bearing mice}

Figure 9 summarizes body weight changes, tumor volume changes, and survival rates of tumor-bearing mice after treatments with varying formulations. According to Figure 9A, the body weight of mice in treatment groups showed no obvious decline as compared with those of normal saline groups. Figure 9B shows tumor volume changes. Results showed that tumor volume ratios at day 12 were $22.38 \pm 5.90$ for normal saline, $19.10 \pm 10.44$ for free epirubicin, $17.12 \pm 5.79$ for epirubicin liposomes, $16.14 \pm 8.92$ for epirubicin plus honokiol liposomes, $15.38 \pm 5.96$ for OCT-modified epirubicin liposomes, and $9.78 \pm 3.19$ for multifunctional targeting epirubicin liposomes. Figure 9C shows survival curves of mice after treatments with the varying formulations. Results showed that multifunctional targeting epirubicin liposomes effectively prolonged the survival time of tumor-bearing mice. 

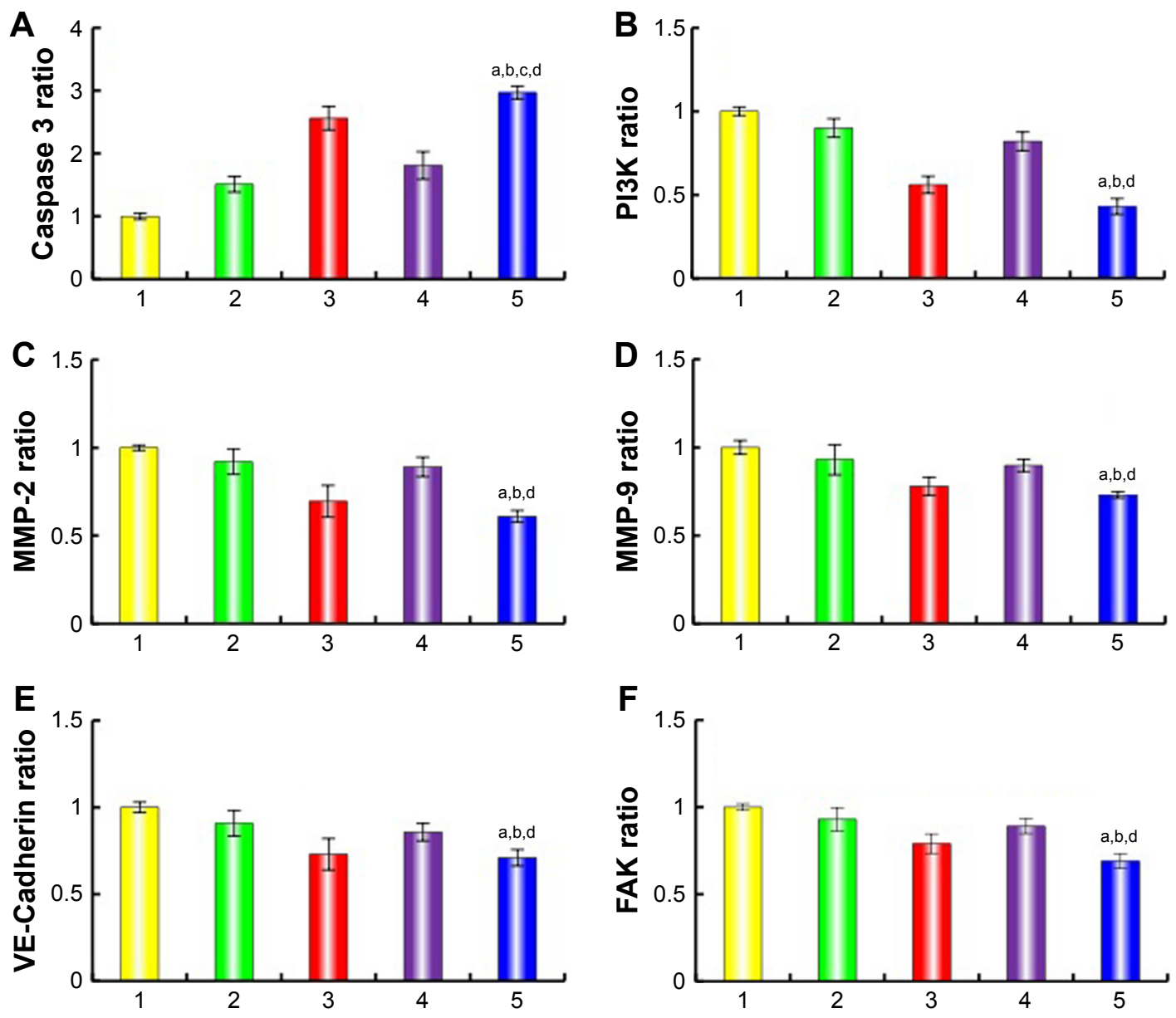

$\begin{array}{lll}\text { 1. Blank control } & \text { 2. Epirubicin liposomes } & \text { 3. Epirubicin plus honokiol liposomes }\end{array}$ 4. OCT-modified epirubicin liposomes

5. Multifunctional targeting epirubicin liposomes

Figure 7 Regulating effects on anti-angiogenesis proteins and apoptotic enzymes (caspase 3) in LLT cells after treatments with the varying liposomes.

Notes: (A) Caspase 3, (B) PI3K, (C) MMP-2, (D) MMP-9, (E) VE-Cadherin, (F) FAK. Data are presented as the mean \pm SD ( $n=3$ ). $p<0.05$; a, vs blank control; b, vs epirubicin liposomes; c, vs epirubicin plus honokiol liposomes; d, vs OCT-modified epirubicin liposomes.

Abbreviations: LLT, Lewis lung tumor; OCT, octreotide.

The survival ranges were 20-31 days for normal saline, 12-29 days for free epirubicin, 22-36 days for epirubicin liposomes, 18-43 days for epirubicin plus honokiol liposomes, 23-39 days for OCT-modified epirubicin liposomes, and 20-48 days for multifunctional targeting epirubicin liposomes. Figure 9D exhibits H\&E staining assay of hearts, livers, spleens, lungs, and kidneys from tumor-bearing mice. Compared with the control group, no appreciable abnormality or noticeable organ damage was observed after treatments with the liposomal formulations. Table 2 shows the hematological parameters, which showed no statistically significant differences between the experimental groups and control group, indicating negligible systemic toxicity at a test dose.

\section{Discussion}

NSCLC represents a predominant subgroup of lung cancer with a leading cause of cancer-related mortality due to tumor metastasis, VM channels, and incomplete surgical excision. Actually, tumor metastasis is responsible for $>90 \%$ of cancer-related mortality. ${ }^{33,34}$ In metastasis, tumor cells go through complicated transitions, including separation from the primary tumor mass, migration and invasion through basement membrane, intravasation into blood vessels, extravasation from blood vessels, arrest at distant organs, and ecesis in the target organs. ${ }^{35,36}$ The formation of new blood vessels is necessary for proliferation and metastasis of cancer cells. In hypoxia, the residual cancer cells could form VM channels to provide nutrients for supporting the growth and recurrence. ${ }^{37}$ Hence, tumor metastasis and VM channels caused poor prognosis in lung cancer patients.

In this study, OCT was modified on the liposomal surface via conjugating with DSPE-PEG ${ }_{2000}$-NHS for targeting somatostatin receptors in tumor cells. MALDI-TOF-MS spectrum analysis confirmed that DSPE-PEG ${ }_{2000}-\mathrm{OCT}$ 


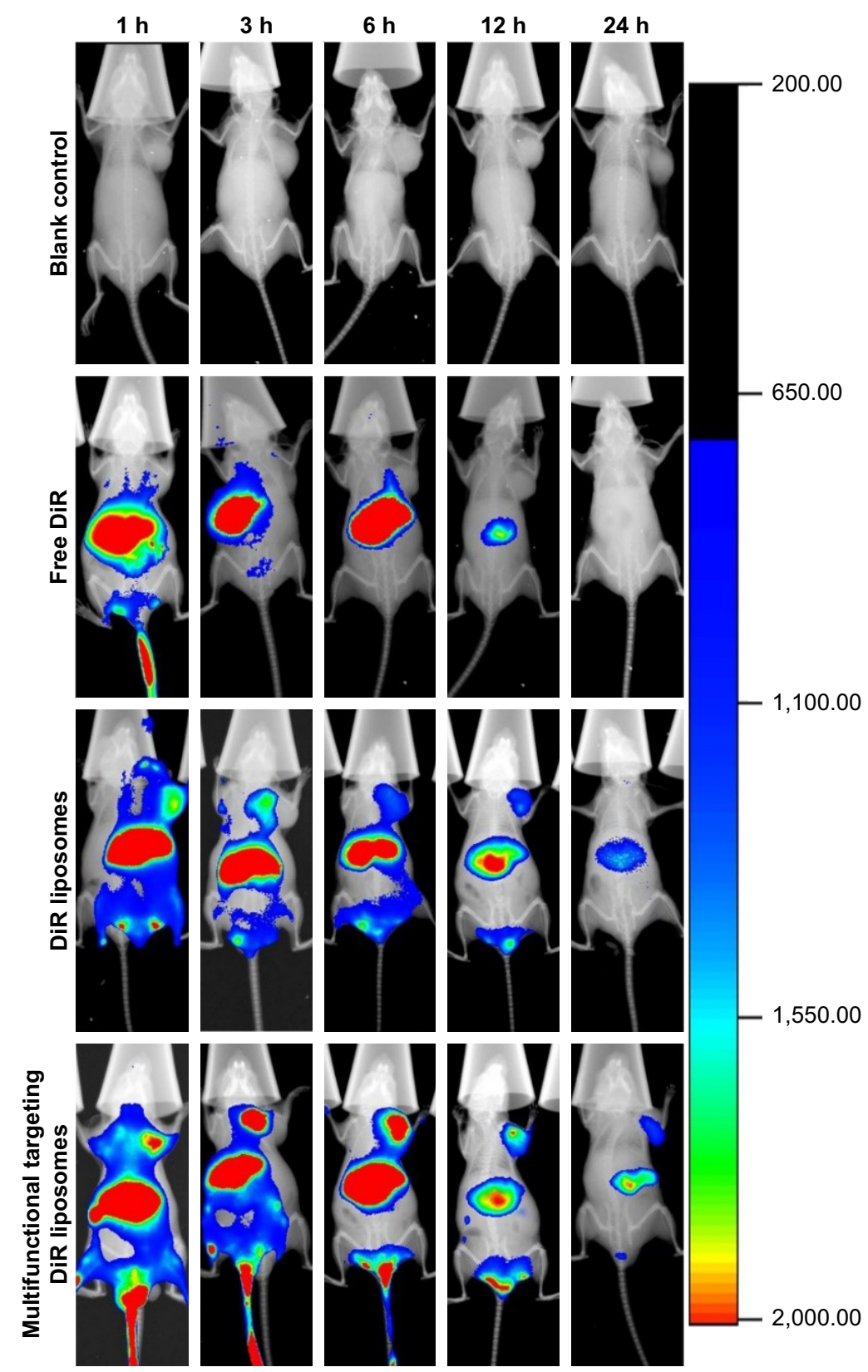

Figure 8 In vivo real-time imaging observation after intravenous administration of the varying formulations $(n=3)$. Abbreviation: DiR, I, I-dioctadecyl-3,3,3,3-tetramethylindotricarbocyanine iodide.

conjugate was successfully synthesized (Figure 1A and B). Physicochemical properties of liposomal formulations are important factors that determine the pharmacokinetics and biodistribution of the nanoparticles. ${ }^{13,38}$ The morphologies of multifunctional targeting epirubicin liposomes were determined by TEM (Figure 2A) and AFM (Figure 2B). Results indicated that the particle size range of liposomes was suitable for the fenestrated vasculatures of cancer tissues via the enhanced permeability retention (EPR) effect. Compared with normal liposomes, the size of multifunctional targeting epirubicin liposomes was not significantly affected by the OCT modification. The zeta potentials of all the liposomal formulations were slightly negative due to the addition of DSPE-PEG $_{2000}$. High EEs and delayed RRs of drugs from the liposomes (Table 1; Figure 2E-H) would be beneficial for preventing the rapid leakage during the process of drug delivery and the accumulation of drug in tumor tissues. ${ }^{39}$

Cytotoxicity assays were performed by an SRB method for evaluating the inhibitory effects on LLT cells. Results showed that epirubicin in combination with different concentrations of honokiol displayed an increasing cytotoxicity to LLT cells compared with epirubicin alone (Figure 3A), indicating that honokiol was beneficial for improving therapeutic effect of epirubicin. The strongest cytotoxic effect on 
LLT cells was observed after incubation with the multifunctional targeting epirubicin liposomes (Figure 3B), suggesting that the modification of OCT could further enhance cellular uptake.

Cellular uptake (Figure 4A-D) confirmed the internalization of the multifunctional targeting epirubicin liposomes. Flow cytometry determination showed that the intracellular fluorescence intensity of epirubicin in multifunctional targeting epirubicin liposomes was higher than those of other liposomes. To investigate the cellular uptake of OCTmodified liposomes via somatostatin receptors, the competitive inhibition study was performed. The differences in cellular uptake between OCT-modified liposomes and ordinary liposomes indicated that the enhanced cellular uptake was due to the receptor-mediated endocytosis. Intracellular distributions were further observed by a fluorescent microscope (Figure 4E). Cell nuclei were stained by Hoechst 33258 and showed blue, and epirubicin showed red. In the merged pictures, purple spots indicated the colocalization of epirubicin into the LLT cells. Results from cellular uptake and colocalization explained the enhanced cytotoxic effect on LLT cells after treatment with multifunctional targeting epirubicin liposomes.

In order to evaluate the destructive effect on angiogenesis, a VM channel model was established with LLT cells in three-dimensional Matrigel (Figure 5A). Results showed that both epirubicin plus honokiol liposomes and multifunctional targeting epirubicin liposomes could significantly inhibit the formation of VM channels, indicating that the addition of honokiol could destruct the VM channels. It was reported that honokiol played an important role in tumor metastasis. ${ }^{40}$ Therefore, we performed Transwell migration assays to evaluate the inhibitory effect on tumor migration. Results indicated that liposomes modified with honokiol could significantly inhibit migration of LLT cells (Figure 5B). Wound healing assays were measured to further evaluate the blocking
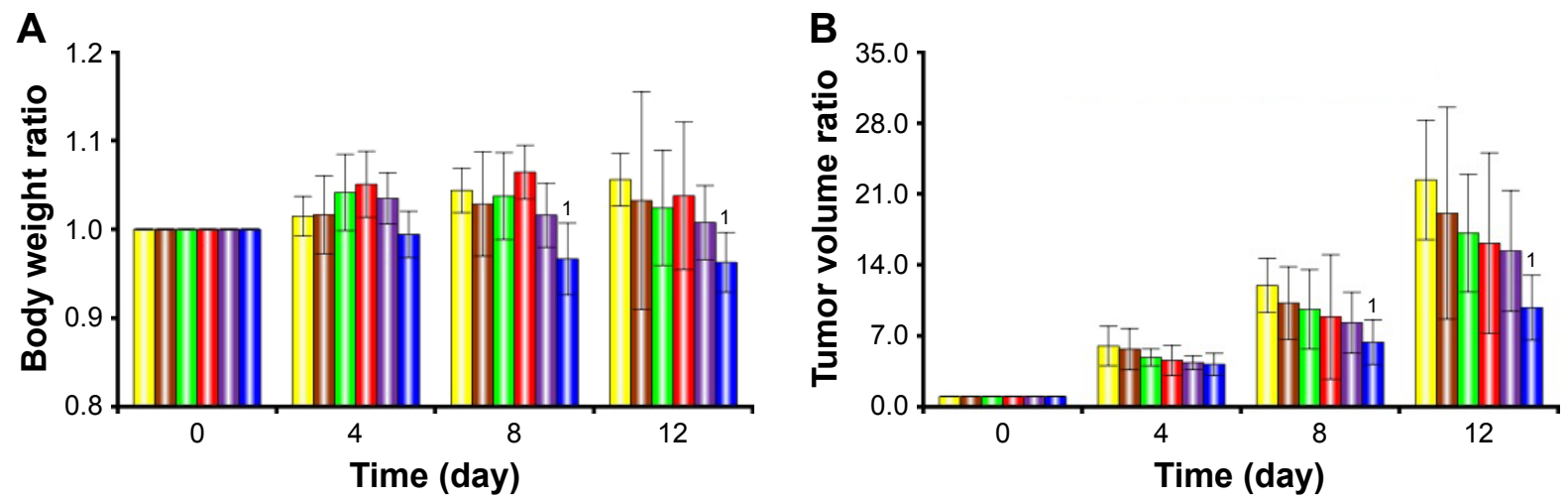

$\square$ Blank control a Free epirubicin $\square$ Epirubicin liposomes a Epirubicin plus honokiol liposomes D OCT-modified epirubicin liposomes $\mathbf{a}$ Multifunctional targeting epirubicin liposomes

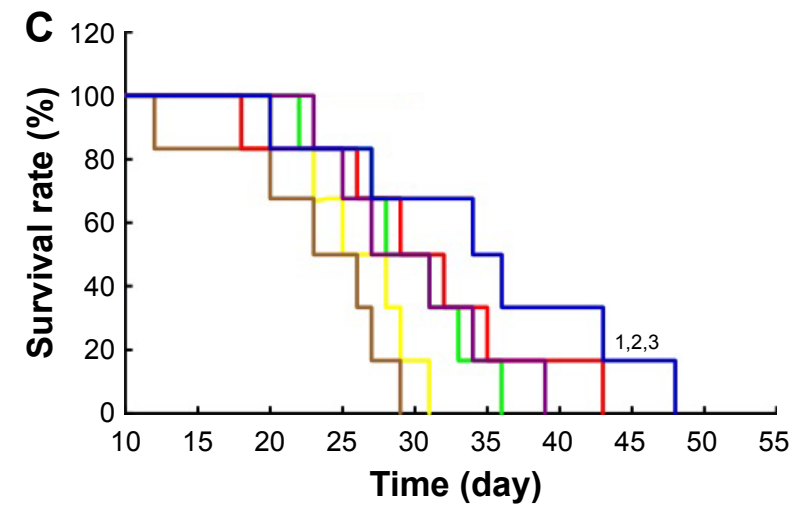

Blank control - Free epirubicin - Epirubicin liposomes
Epirubicin plus honokiol liposomes - OCT-modified epirubicin liposomes
Multifunctional targeting epirubicin liposomes


D
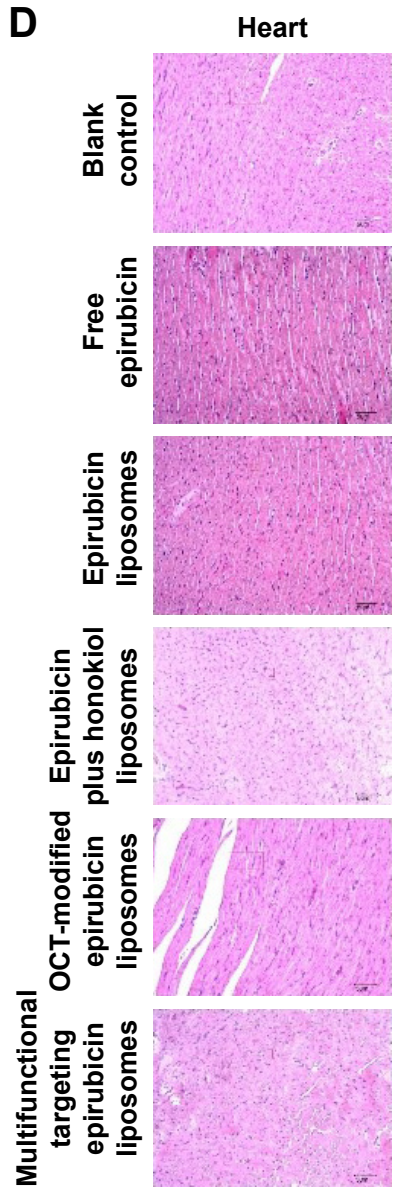
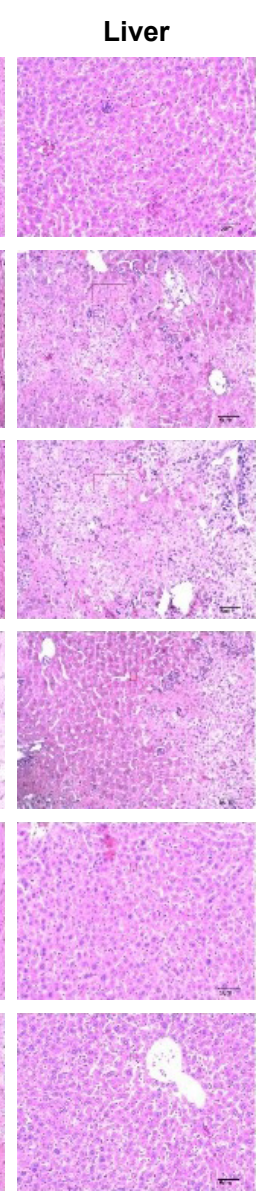
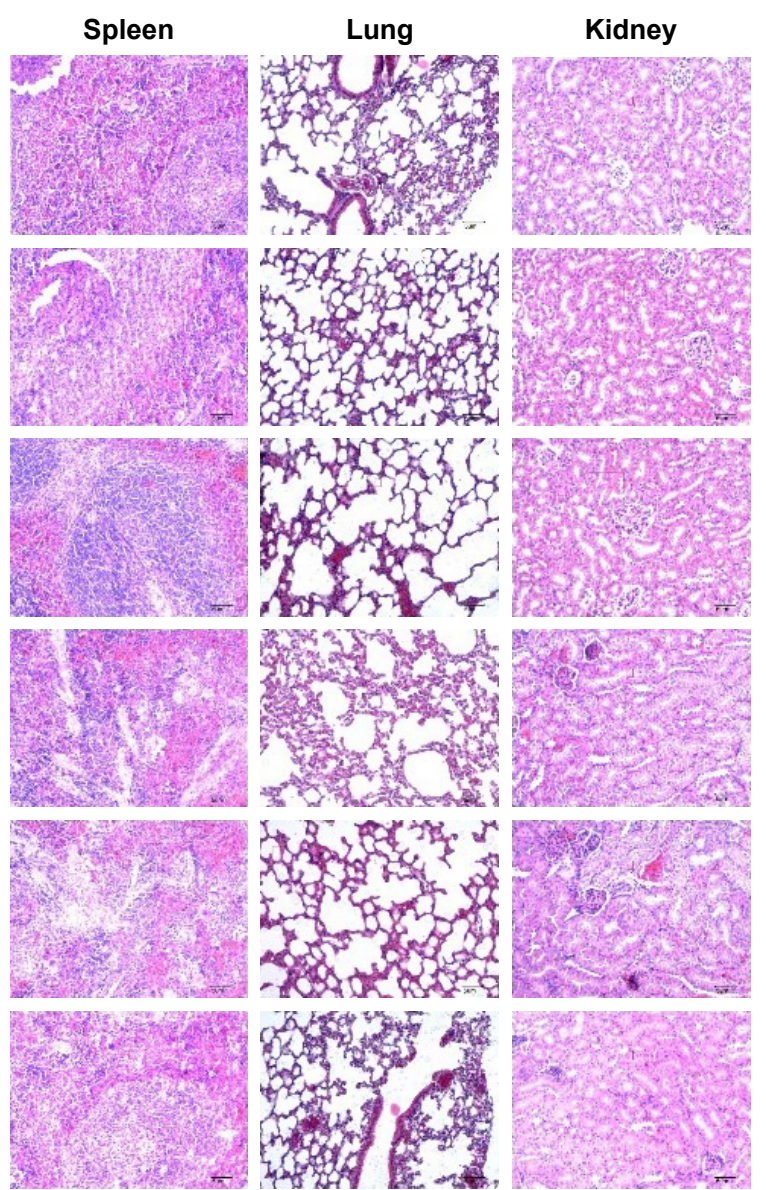

Figure 9 Antitumor effects in LLT cells of xenograft mice after treatments with the varying formulations.

Notes: (A) Body weight changes, (B) tumor volume changes, (C) survival rates, (D) H\&E staining assay. Magnification $\times 400$. $p<0.05$; I, vs blank control; 2 , vs free epirubicin; 3, vs epirubicin liposomes.

Abbreviations: LLT, Lewis lung tumor; OCT, octreotide.

Table 2 Blood examinations of tumor-bearing mice

\begin{tabular}{lllllll}
\hline Assay & $\mathrm{I}$ & $\mathbf{2}$ & $\mathbf{3}$ & $\mathbf{4}$ & $\mathbf{5}$ & $\mathbf{6}$ \\
\hline WBC & $5.88 \pm 1.3 \mathrm{I}$ & $5.58 \pm 1.97$ & $7.10 \pm 2.69$ & $5.23 \pm 1.67$ & $7.10 \pm 1.48$ & $9.55 \pm 3.00$ \\
RBC & $4.66 \pm 2.07$ & $8.35 \pm 0.45$ & $7.38 \pm 1.15$ & $8.29 \pm 0.60$ & $8.54 \pm 0.33$ & $8.52 \pm 0.27$ \\
HGB & $140.50 \pm 10.63$ & $137.75 \pm 14.86$ & $116.50 \pm 19.74$ & $142.75 \pm 4.72$ & $139.00 \pm 2.45$ & $143.25 \pm 5.12$ \\
HCT & $37.88 \pm 3.01$ & $38.83 \pm 3.08$ & $33.60 \pm 5.37$ & $39.25 \pm 2.19$ & $38.75 \pm 1.04$ & $40.28 \pm 0.76$ \\
MCV & $46.43 \pm 1.18$ & $46.48 \pm 1.96$ & $45.48 \pm 0.30$ & $47.40 \pm 0.88$ & $45.40 \pm 0.59$ & $47.33 \pm 1.28$ \\
MCH & $16.58 \pm 0.67$ & $16.48 \pm 0.99$ & $15.75 \pm 0.33$ & $17.28 \pm 0.91$ & $16.28 \pm 0.42$ & $16.85 \pm 1.10$ \\
MCHC & $358.00 \pm 16.63$ & $354.25 \pm 13.28$ & $346.25 \pm 8.18$ & $364.25 \pm 12.97$ & $359.00 \pm 5.77$ & $355.75 \pm 17.39$ \\
RDW & $13.60 \pm 0.98$ & $13.38 \pm 1.34$ & $14.38 \pm 0.32$ & $14.13 \pm 1.00$ & $14.20 \pm 1.27$ & $13.68 \pm 0.38$ \\
PLT & $338.25 \pm 95.10$ & $366.00 \pm 185.05$ & $616.00 \pm 115.64$ & $390.00 \pm 81.06$ & $462.50 \pm 120.49$ & $475.00 \pm 52.85$ \\
PCT & $0.18 \pm 0.04$ & $0.14 \pm 0.08$ & $0.24 \pm 0.05$ & $0.15 \pm 0.03$ & $0.18 \pm 0.05$ & $0.19 \pm 0.02$ \\
MPV & $3.88 \pm 0.32$ & $4.10 \pm 0.51$ & $3.98 \pm 0.40$ & $3.95 \pm 0.06$ & $3.95 \pm 0.17$ & $4.15 \pm 0.13$ \\
PDW & $15.75 \pm 1.36$ & $14.33 \pm 0.96$ & $13.83 \pm 0.51$ & $14.50 \pm 0.84$ & $14.10 \pm 0.98$ & $14.65 \pm 0.29$ \\
LYM & $1.10 \pm 0.65$ & $0.83 \pm 0.72$ & $1.10 \pm 0.78$ & $0.85 \pm 0.38$ & $1.58 \pm 0.31$ & $1.98 \pm 0.62$ \\
MID & $0.35 \pm 0.21$ & $0.30 \pm 0.08$ & $0.23 \pm 0.15$ & $0.68 \pm 0.59$ & $0.50 \pm 0.54$ & $0.75 \pm 0.79$ \\
GRN & $4.80 \pm 1.45$ & $4.45 \pm 1.18$ & $5.78 \pm 1.93$ & $3.70 \pm 0.91$ & $5.03 \pm 1.28$ & $6.83 \pm 1.90$ \\
LYM\% & $14.13 \pm 5.49$ & $12.65 \pm 6.44$ & $14.63 \pm 5.46$ & $15.88 \pm 3.07$ & $22.15 \pm 3.17$ & $20.78 \pm 2.10$ \\
MID\% & $4.10 \pm 0.84$ & $5.30 \pm 1.00$ & $3.18 \pm 1.75$ & $10.90 \pm 7.98$ & $6.18 \pm 6.68$ & $6.83 \pm 5.27$ \\
GRN\% & $73.46 \pm 7.04$ & $82.05 \pm 5.90$ & $82.20 \pm 4.68$ & $73.23 \pm 10.21$ & $71.68 \pm 9.39$ & $72.40 \pm 6.36$ \\
\hline Not & & & & & & \\
\hline
\end{tabular}

Notes: Data are presented as mean \pm SD $(n=3)$. I. Normal saline; 2. Free epirubicin; 3. Epirubicin liposomes; 4. HNK-modified epirubicin liposomes; 5 . OCT-modified epirubicin liposomes; 6. Multifunctional targeting epirubicin liposomes.

Abbreviations: WBC, White blood cells; RBC, Red blood cells; HGB, Hemoglobin; HCT, Hematocrit; MCV, Mean corpuscular volume; MCH, Mean corpuscular hemoglobin; MCHC, Mean corpuscular hemoglobin concentration; RDW, Red cell distribution width; PLT, Platelets; PCT, Plateletcrit; MPV, Mean platelet volume; PDW, Platelet distribution width; LYM, Lymphocyte; MID, Intermediate cell; GRN, Neutrophil granulocyte. 
effects on tumor migration (Figure 6). An obvious blocking effect on wound healing was observed after incubation with multifunctional targeting epirubicin liposomes, which further verified the capability of inhibiting tumor migration.

Tumor metastasis is initiated by invasion and migration of tumor cells, and the metastatic cascade is originated by a series of protein expression alterations. PI3K pathway has been implicated in driving metastatic phenotype in cancers. PI3K has pleiotropic effects, including migration, cell adhesion, and invasion. PI3K pathway interacts with FAK, and the interaction promotes cell adhesion and movement. ${ }^{41,42}$ FAK is a nonreceptor tyrosine kinase and primarily localized to cell matrix adhesions. It plays a prominent role in tumor progression and metastasis through the regulation of tumor migration, invasion, and angiogenesis. ${ }^{43}$ VE-Cadherin is an endothelial cell-specific cadherin and located at intercellular adherens junctions. It is considered to be an important agent that is indirectly responsible for tumor metastasis due to the involvement in angiogenesis. ${ }^{44}$ MMP-2 and MMP-9 are proteolytic enzymes overexpressed in lung cancer and lead to enhance tumor migration and invasion. ${ }^{45}$ The function of the MMPs is to degrade the environmental extracellular matrix and the basement membrane. The decreased expressions of MMPs have been shown to suppress tumor metastasis. In this study, the incorporation of honokiol notably suppressed the tumor migration and VM channels via downregulating the expressions of PI3K, MMP-2, MMP-9, VE-Cadherin, and FAK (Figure 7B-F). The destruction of VM channels would interrupt the nutrient and blood transporting to the extravascular core region of the tumor and then decrease invasion and metastasis of the tumor cells. ${ }^{18}$ Caspase 3 is categorized as an effector caspase that can cleave various cellular substrates and induce apoptosis. ${ }^{46}$ Results revealed that caspase 3 was significantly upregulated by the liposomal formulations (Figure 7A).

Distribution of the liposomes in vivo was measured by a noninvasive optical imaging system. Results showed that multifunctional targeting DiR liposomes showed high tumortargeting efficiency and effective accumulation in tumor sites up to 24 hours (Figure 8). The high tumor-targeting ability of multifunctional targeting DiR liposomes may be connected with the combination of the EPR effect and receptor-mediated cellular uptake. Although in vitro data provide an important preliminary background to advance the potential use of the multifunctional targeting epirubicin liposomes, these results should further be confirmed and validated in vivo. In this study, antitumor efficacy was evaluated on tumor-bearing mice by evaluating body weights, tumor volumes, and survival curves. Results from tumor volumes and survival curves showed that multifunctional targeting epirubicin liposomes showed a significant antitumor effect (Figure 9B and C). Body weight ratios, H\&E staining, and the analysis of hematological parameters showed that there was no obvious indication of acute toxicity after treatment with the multifunctional targeting epirubicin liposomes (Figure 9A and D; Table 2).

\section{Conclusion}

In this study, we prepared a kind of multifunctional targeting epirubicin liposomes and evaluated the destroying effects on VM channels, the blocking effects on tumor metastasis, and the antitumor efficacy in vitro and in vivo. Possible action mechanisms for the enhanced antitumor efficacy could attribute to the following aspects: 1) the size of liposomes $(\sim 100 \mathrm{~nm})$ was suitable for the fenestrated vasculatures of tumor tissues via the EPR effect; 2) the modification of OCT on the liposomal surface increased the cellular uptake via a receptor-mediated endocytosis; 3 ) the addition of honokiol destroyed VM channels and blocked tumor metastasis; 4) the expressions of PI3K, MMP-2, MMP-9, VE-Cadherin, and FAK were downregulated after treatment with multifunctional targeting epirubicin liposomes; 5) multifunctional targeting epirubicin liposomes induced apoptosis of LLT cells via activating caspase 3 . In addition, multifunctional targeting epirubicin liposomes showed negligible systemic toxicity at a test dose. Therefore, the multifunctional targeting epirubicin liposomes may provide an effective strategy for the treatment of NSCLC.

\section{Acknowledgments}

This work was supported by the grants from the National Natural Science Foundation of China (Grant No 81673603), the Key Laboratory Project of Education Department of Liaoning Province (Grant No LZ2015053), and the Liaoning Natural Science Foundation (Grant No 2014020046).

\section{Disclosure}

The authors report no conflicts of interest in this work.

\section{References}

1. Han HW, Hsu SH. Chitosan-hyaluronan based 3D co-culture platform for studying the crosstalk of lung cancer cells and mesenchymal stem cells. Acta Biomater. 2016;42:157-167.

2. Biswas S, Deshpande PP, Perche F, Dodwadkar NS, Sane SD, Torchilin VP. Octa-arginine-modified pegylated liposomal doxorubicin: an effective treatment strategy for non-small cell lung cancer. Cancer Lett. 2013;335(1):191-200. 
3. Zhou G, Zhang F, Guo Y, et al. miR-200c enhances sensitivity of drug-resistant non-small cell lung cancer to gefitinib by suppression of $\mathrm{PI} 3 \mathrm{~K} /$ Akt signaling pathway and inhibites cell migration via targeting ZEB1. Biomed Pharmacother. 2017;85:113-119.

4. Wu H, Zhong Q, Zhong R, et al. Preparation and antitumor evaluation of self-assembling oleanolic acid-loaded Pluronic P105/d- $\alpha$-tocopheryl polyethylene glycol succinate mixed micelles for non-small-cell lung cancer treatment. Int J Nanomedicine. 2016;11:6337-6352.

5. Zarogoulidis P, Chinelis P, Athanasiadou A, et al. Possible adverse effects of immunotherapy in non-small cell lung cancer; treatment and follow-up of three cases. Respir Med Case Rep. 2017;22:101-105.

6. Li C, Hu J, Li W, Song G, Shen J. Combined bortezomib-based chemotherapy and p53 gene therapy using hollow mesoporous silica nanospheres for p53 mutant non-small cell lung cancer treatment. Biomater Sci. 2016;5(1):77-88.

7. Zhu Y, Zhu R, Wang M, et al. Anti-metastatic and anti-angiogenic activities of core-shell SiO2@LDH loaded with etoposide in non-small cell lung cancer. Adv Sci (Weinh). 2016;3(11):1600229.

8. Maniotis AJ, Folberg R, Hess A, et al. Vascular channel formation by human melanoma cells in vivo and in vitro: vasculogenic mimicry. Am J Pathol. 1999;155(3):739-752.

9. Huang D, Zhang S, Zhong T, et al. Multi-targeting NGR-modified liposomes recognizing glioma tumor cells and vasculogenic mimicry for improving anti-glioma therapy. Oncotarget. 2016;7(28): 43616-43628.

10. Jue C, Lin C, Zhisheng Z, et al. Notch1 promotes vasculogenic mimicry in hepatocellular carcinoma by inducing EMT signaling. Oncotarget. 2017;8(2):2501-2513.

11. Rong X, Huang B, Qiu S, Li X, He L, Peng Y. Tumor-associated macrophages induce vasculogenic mimicry of glioblastoma multiforme through cyclooxygenase-2 activation. Oncotarget. 2016;7(51): 83976-83986.

12. Guo Z, He B, Yuan L, et al. Dual targeting for metastatic breast cancer and tumor neovasculature by EphA2-mediated nanocarriers. Int $J$ Pharm. 2015;493(1-2):380-389.

13. Liu Y, Mei L, Yu Q, et al. Multifunctional tandem peptide modified paclitaxel-loaded liposomes for the treatment of vasculogenic mimicry and cancer stem cells in malignant glioma. ACS Appl Mater Interfaces. 2015;7(30):16792-16801.

14. Ma JL, Han SX, Zhu Q, et al. Role of Twist in vasculogenic mimicry formation in hypoxic hepatocellular carcinoma cells in vitro. Biochem Biophys Res Commun. 2011;408(4):686-691.

15. Zhang Y, Thayele Purayil H, Black JB, et al. Prostaglandin E2 receptor 4 mediates renal cell carcinoma intravasation and metastasis. Cancer Lett. 2017;391:50-58.

16. Kang H, Zhang J, Wang B, et al. Puerarin inhibits M2 polarization and metastasis of tumor-associated macrophages from NSCLC xenograft model via inactivating MEK/ERK 1/2 pathway. Int J Oncol. 2017;50(2): 545-554

17. Zhang L, Wang Y, Xia T, et al. Suppression for lung metastasis by depletion of collagen I and lysyl oxidase via losartan assisted with paclitaxel-loaded pH-sensitive liposomes in breast cancer. Drug Deliv. 2016;23(8):2970-2979.

18. Song CK, Lee JH, Jahn A, et al. In vitro and in vivo evaluation of N,N,N-trimethylphytosphingosine-iodide (TMP) in liposomes for the treatment of angiogenesis and metastasis. Int J Pharm . 2012;434(1-2): 191-198

19. Zang M, Zhang Y, Zhang B, et al. CEACAM6 promotes tumor angiogenesis and vasculogenic mimicry in gastric cancer via FAK signaling. Biochim Biophys Acta. 2015;1852(5):1020-1028.

20. Su Z, Shi Y, Xiao Y, et al. Effect of octreotide surface density on receptor-mediated endocytosis in vitro and anticancer efficacy of modified nanocarrier in vivo after optimization. Int $J$ Pharm. 2013; 447(1-2):281-292.

21. Zhang HY, Xu WQ, Wang YW, et al. Tumor targeted delivery of octreotide-periplogenin conjugate: synthesis, in vitro and in vivo evaluation. Int J Pharm. 2016;502(1-2):98-106.
22. Chen X, Zhang XY, Shen Y, Fan LL, Ren ML, Wu YP. Synthetic paclitaxel-octreotide conjugate reversing the resistance of A2780/Taxol to paclitaxel in xenografted tumor in nude mice. Oncotarget. 2016; 7(50):83451-83461.

23. Iwase Y, Maitani Y. Octreotide-targeted liposomes loaded with CPT-11 enhanced cytotoxicity for the treatment of medullary thyroid carcinoma. Mol Pharm. 2011;8(2):330-337.

24. Wang M, Shan F, Zou Y, et al. Pharmacokinetic and pharmacodynamic study of a phospholipid-based phase separation gel for once a month administration of octreotide. J Control Release. 2016;230:45-56.

25. Gou M, Zheng L, Peng X, et al. Poly(epsilon-caprolactone)-poly(ethylene glycol)-poly(epsilon-caprolactone) (PCL-PEG-PCL) nanoparticles for honokiol delivery in vitro. Int J Pharm. 2009;375(1-2):170-176.

26. Singh T, Katiyar SK. Honokiol inhibits non-small cell lung cancer cell migration by targeting PGE(2)-mediated activation of beta-catenin signaling. PLoS One. 2013;8(4):e60749.

27. Zheng X, Kan B, Gou M, et al. Preparation of MPEG-PLA nanoparticle for honokiol delivery in vitro. Int J Pharm. 2010;386(1-2):262-267.

28. Zhang CX, Zhao WY, Liu L, et al. A nanostructure of functional targeting epirubicin liposomes dually modified with aminophenyl glucose and cyclic pentapeptide used for brain glioblastoma treatment. Oncotarget. 2015;6(32):32681-32700.

29. Zhou S, Zhang T, Peng B, et al. Targeted delivery of epirubicin to tumorassociated macrophages by sialic acid-cholesterol conjugate modified liposomes with improved antitumor activity. Int J Pharm. 2017;523(1): 203-216.

30. Song XL, Liu S, Jiang Y, et al. Targeting vincristine plus tetrandrine liposomes modified with DSPE-PEG2000-transferrin in treatment of brain glioma. Eur J Pharm Sci. 2016;96:129-140.

31. Li XT, Zhou ZY, Jiang Y, et al. PEGylated VRB plus quinacrine cationic liposomes for treating non-small cell lung cancer. J Drug Target. 2015;23(3):232-243.

32. Li XT, He ML, Zhou ZY, Jiang Y, Cheng L. The antitumor activity of PNA modified vinblastine cationic liposomes on Lewis lung tumor cells: in vitro and in vivo evaluation. Int J Pharm. 2015;487(1-2):223-233.

33. Guo L, Fan L, Ren J, et al. Combination of TRAIL and actinomycin D liposomes enhances antitumor effect in non-small cell lung cancer. Int J Nanomedicine. 2012;7:1449-1460.

34. Wang D, Lin Y, Gao B, et al. Reduced expression of FADS1 predicts worse prognosis in non-small-cell lung cancer. J Cancer. 2016;7(10): 1226-1232.

35. Cao W, Zheng W, Chen T. Ruthenium polypyridyl complex inhibits growth and metastasis of breast cancer cells by suppressing FAK signaling with enhancement of TRAIL-induced apoptosis. Sci Rep. 2015;5:9157.

36. Tacconi C, Correale C, Gandelli A, et al. Vascular endothelial growth factor $\mathrm{C}$ disrupts the endothelial lymphatic barrier to promote colorectal cancer invasion. Gastroenterology. 2015;148(7):1438.e8-1451.e8.

37. Lu XS, Sun W, Ge CY, Zhang WZ, Fan YZ. Contribution of the PI3K/ MMPs/Ln-5 $\gamma 2$ and EphA2/FAK/Paxillin signaling pathways to tumor growth and vasculogenic mimicry of gallbladder carcinomas. Int $J$ Oncol. 2013;42(6):2103-2115.

38. Zhang L, Yao HJ, Yu Y, et al. Mitochondrial targeting liposomes incorporating daunorubicin and quinacrine for treatment of relapsed breast cancer arising from cancer stem cells. Biomaterials. 2012;33(2): $565-582$.

39. Liu Y, Lu WL, Guo J, et al. A potential target associated with both cancer and cancer stem cells: a combination therapy for eradication of breast cancer using vinorelbine stealthy liposomes plus parthenolide stealthy liposomes. J Control Release. 2008;129(1):18-25.

40. Hu J, Chen LJ, Liu L, et al. Liposomal honokiol, a potent antiangiogenesis agent, in combination with radiotherapy produces a synergistic antitumor efficacy without increasing toxicity. Exp Mol Med. 2008;40(6):617-628.

41. Burrows N, Telfer B, Brabant G, Williams KJ. Inhibiting the phosphatidylinositide 3-kinase pathway blocks radiation-induced metastasis associated with Rho-GTPase and Hypoxia-inducible factor-1 activity. Radiother Oncol. 2013;108(3):548-553. 
42. Pylayeva Y, Gillen KM, Gerald W, Beggs HE, Reichardt LF, Giancotti FG. Ras- and PI3K-dependent breast tumorigenesis in mice and humans requires focal adhesion kinase signaling. J Clin Invest. 2009;119(2):252-266.

43. Niit M, Hoskin V, Carefoot E, et al. Cell-cell and cell-matrix adhesion in survival and metastasis: Stat3 versus Akt. Biomol Concepts. 2015;6(5-6): 383-399.

44. Rodriguez MI, Peralta-Leal A, O'Valle F, et al. PARP-1 regulates metastatic melanoma through modulation of vimentin-induced malignant transformation. PLoS Genet. 2013;9(6):e1003531.
45. Shen KH, Hung JH, Chang CW, Weng YT, Wu MJ, Chen PS. Solasodine inhibits invasion of human lung cancer cell through downregulation of miR-21 and MMPs expression. Chem Biol Interact. 2017;268:129-135.

46. Liu YR, Sun B, Zhao XL, et al. Basal caspase-3 activity promotes migration, invasion, and vasculogenic mimicry formation of melanoma cells. Melanoma Res. 2013;23(4):243-253. 


\section{Supplementary materials}
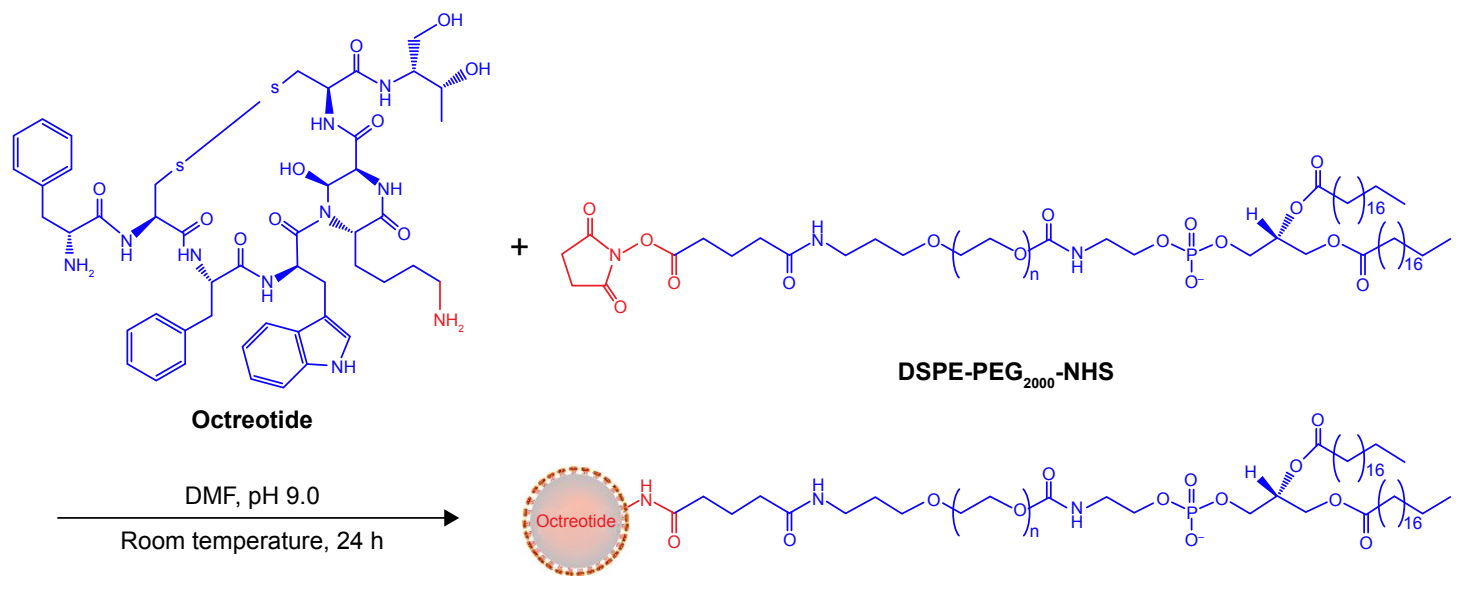

DSPE-PEG ${ }_{2000}-\mathrm{OCT}$

Figure SI Synthetic routes for DSPE-PEG ${ }_{2000}-\mathrm{OCT}$ conjugates.

Abbreviations: DMF, dimethylformamide; DSPE-PEG ${ }_{2000}$, polyethylene glycol-distearoyl phosphatidylethanolamine; NHS, N-hydroxysuccinimide; OCT, octreotide.

Table SI Formulation composition of liposomes

\begin{tabular}{|c|c|c|c|c|c|}
\hline \multirow[t]{2}{*}{ Liposomes } & \multicolumn{3}{|c|}{ Formulation composition (molar ratio) } & \multirow[t]{2}{*}{ Honokiol } & \multirow{2}{*}{$\begin{array}{l}\text { DSPE- } \\
\text { PEG }_{2000}-O C T\end{array}$} \\
\hline & EPC & Cholesterol & DSPE-PEG $_{2000}$ & & \\
\hline Epirubicin liposomes & 60 & 40 & 2 & - & 3 \\
\hline Epirubicin plus honokiol liposomes & 60 & 40 & 2 & 5 & 3 \\
\hline OCT-modified epirubicin liposomes & 60 & 40 & 2 & - & 3 \\
\hline Multifunctional targeting epirubicin liposomes & 60 & 40 & 2 & 5 & 3 \\
\hline
\end{tabular}

Abbreviations: DSPE-PEG ${ }_{2000}$, polyethylene glycol-distearoyl phosphatidylethanolamine; EPC, egg yolk phosphatidylcholine; OCT, octreotide.

\section{Publish your work in this journal}

The International Journal of Nanomedicine is an international, peerreviewed journal focusing on the application of nanotechnology in diagnostics, therapeutics, and drug delivery systems throughou the biomedical field. This journal is indexed on PubMed Central, MedLine, CAS, SciSearch ${ }^{\circledR}$, Current Contents ${ }^{\circledR} /$ Clinical Medicine,
Journal Citation Reports/Science Edition, EMBase, Scopus and the Elsevier Bibliographic databases. The manuscript management system is completely online and includes a very quick and fair peer-review system, which is all easy to use. Visit http://www.dovepress.com/ testimonials.php to read real quotes from published authors.

Submit your manuscript here: http://www.dovepress.com/international-journal-of-nanomedicine-journal 